\title{
ARTIFICIAL GEOTHERMAL ENERGY POTENTIAL OF STEAM-FLOODED HEAVY OIL RESERVOIRS
}

\author{
A Thesis \\ by \\ AKKHARACHAI LIMPASURAT
}

\author{
Submitted to the Office of Graduate Studies of \\ Texas A\&M University \\ in partial fulfillment of the requirements for the degree of \\ MASTER OF SCIENCE
}

August 2010

Major Subject: Petroleum Engineering 


\title{
ARTIFICIAL GEOTHERMAL ENERGY POTENTIAL OF STEAM-FLOODED HEAVY OIL RESERVOIRS
}

A Thesis

by

\section{AKKHARACHAI LIMPASURAT}

\author{
Submitted to the Office of Graduate Studies of \\ Texas A\&M University \\ in partial fulfillment of the requirements for the degree of \\ MASTER OF SCIENCE
}

\begin{abstract}
Approved by:
Co-Chairs of Committee, Gioia Falcone

Catalin Teodoriu

Committee Member, Maria Barrufet

Head of Department, Stephen Holditch
\end{abstract}

August 2010

Major Subject: Petroleum Engineering 


\begin{abstract}
Artificial Geothermal Energy Potential of Steam-flooded Heavy Oil Reservoirs.

(August 2010)

Akkharachai Limpasurat, B.Eng., Chulalongkorn University

Co-Chairs of Advisory Committee: Dr. Gioia Falcone

Dr. Catalin Teodoriu
\end{abstract}

This study presents an investigation of the concept of harvesting geothermal energy that remains in heavy oil reservoirs after abandonment when steamflooding is no longer economics. Substantial heat that has accumulated within reservoir rock and its vicinity can be extracted by circulating water relatively colder than reservoir temperature. We use compositional reservoir simulation coupled with a semianalytical equation of the wellbore heat loss approximation to estimate surface heat recovery. Additionally, sensitivity analyses provide understanding of the effect of various parameters on heat recovery in the artificial geothermal resources. Using the current state-of-art technology, the cumulative electrical power generated from heat recovered is about $246 \mathrm{MWhr}$ accounting for $90 \%$ downtime.

Characteristics of heat storage within the reservoir rock were identified. The factors with the largest impact on the energy recovery during the water injection phase are the duration of the steamflood (which dictates the amount of heat accumulated in the reservoir) and the original reservoir energy in place. Outlet reservoir-fluid temperatures are used to approximate heat loss along the wellbore and estimate surface fluid temperature using the semianalytical approaches. For the injection well with insulation, results indicate that differences in fluid temperature between surface and bottomhole are negligible. However, for the conventional production well, heat loss is estimated around $13 \%$ resulting in the average surface temperature of $72^{\circ} \mathrm{C}$.

Producing heat can be used in two applications: direct uses and electricity generation. For the electricity generation application that is used in the economic consideration, the 
net electrical power generated by this arrival fluid temperature is approximately $3 \mathrm{~kW}$ per one producing pattern using Ener-G-Rotors. 


\section{ACKNOWLEDGEMENTS}

I would like to thank my committee chairs, Dr. Gioia Falcone and Dr. Catalin Teodoriu, and my committee member, Dr. Maria Barrufet, for their guidance and kindest support throughout the course of this research. My appreciation also goes to Dr. Jader Barbosa at UFSC in Brazil who advised ways to estimate wellbore heat transfers more correctly. Thanks also go to the department faculty, staff, all my research group members, and friends for making my time at Texas A\&M University a great experience.

Finally, thanks to my mother, father, and sister for their consistent encouragement. 


\section{NOMENCLATURE}

C

d

$\mathrm{D}$

$\mathrm{D}_{\mathrm{e}}$

$E_{c}$

$e$

g

$\mathrm{g}_{\mathrm{c}}$

$\mathrm{g}_{G}$

$h$

$h_{1}$

$\mathrm{h}_{2}$

HP

J

$\mathrm{L}$

$M_{\sigma}$

$M_{\text {rock }}$

$p_{\mathrm{F}}$

$\mathrm{q}$

Q

$\dot{Q}$

$q_{\mathrm{F}}$

$\mathrm{r}$

$S_{i}$

$\mathrm{T}$
Heat capacity, Btu/lb- ${ }^{\circ} \mathrm{F}$

Heat diffusion length $=\frac{\sqrt{\alpha t}}{2}, \mathrm{ft}$

Depth, ft

$\mathrm{d}_{\mathrm{ci}}-\mathrm{d}_{\mathrm{to}}, \mathrm{ft}$

Energy stored in the cap or base rock

Internal energy per unit mass, Btu/l $\mathrm{b}_{\mathrm{m}}$

Gravity acceleration constant, $\mathrm{ft} / \mathrm{s}^{2}$

Conversion factor in Newton's law of motion, $32.174 \mathrm{lb}_{\mathrm{m}}-\mathrm{ft} / \mathrm{lb}_{\mathrm{f}}-\mathrm{s}^{2}$

Geothermal gradient, ${ }^{\circ} \mathrm{F} / \mathrm{ft}$

Enthalpy, Btu/lbm

Convection heat transfer of tubing fluid $=0.115 \frac{k_{f}}{r_{t i}} N_{R e^{0.8}} N_{P r}{ }^{0.4}$

Convection heat transfer of annular fluid $=$

$0.032 \frac{k_{f}}{D_{e}}\left(\frac{D_{e} G}{\mu}\right)^{0.8}\left(\frac{C_{f} \mu}{k_{f}}\right)^{0.4}$

Power consumption, hp

Mechanical equivalent of heat, $778 \mathrm{ft}-\mathrm{lb}_{\mathrm{f}} / \mathrm{btu}$

Measured well depth, $\mathrm{ft}$

Volumetric heat capacity of the reservoir solid, Btu/ $/ \mathrm{ft}^{3}{ }^{\circ} \mathrm{F}$

Heated rock mass, $\mathrm{lb}_{\mathrm{m}}$

Fitting parameter

Volumetric flow rate, Bbl/day

Pumping rate, Bbl/day

Heat loss rate, Btu/day

Fitting parameter

Radius, $\mathrm{ft}$

Saturation of the $i^{\text {th }}$ phase

Temperature, ${ }^{\circ} \mathrm{F}$ 
$t_{D}$

$u_{T}$

$u_{\lambda x}$

$\mathrm{u}$

$\mathrm{U}$

W

Z

Z

$\beta$

$\delta$

$\Delta \mathrm{P}$

$\Delta \mathrm{Z}$

$\frac{\partial T}{\partial x}$

$\eta$

$\lambda$

$\rho$

$\tau$

$\alpha$

$\theta$

$\phi$

\section{Subscripts}

b

ci
Time, day

Fluid temperature in borehole, ${ }^{\circ} \mathrm{F}$

Adjusted geothermal temperature, ${ }^{\circ} \mathrm{F} / \mathrm{ft}$

Dimensionless time, $\frac{k_{e} t}{\rho_{e} C_{e} r_{w b}{ }^{2}}$

Convective energy flux, Btu/ $\mathrm{ft}^{2}$-day

Heat flux by conduction, $\mathrm{Btu} / \mathrm{ft}^{2}-{ }^{\circ} \mathrm{F}$-day

Volumetric flux, Bbl/day

Overall heat transfer coefficient, Btu/ $\mathrm{ft}^{2}{ }^{\circ} \mathrm{F}$-day

Mass flow rate, $1 \mathrm{~b}_{\mathrm{m}} /$ day

Distance from the interface, $\mathrm{ft}$

Ramey equation parameter

Wellbore inclination, degree

Moving thermal penetration thickness, $\mathrm{ft}$

Lifting power, psi

Formation thickness, $\mathrm{ft}$

Temperature gradient in the $\mathrm{x}$ direction, ${ }^{\circ} \mathrm{F} / \mathrm{ft}$

Efficiency of transmitting heat into electricity

Thermal conductivity, Btu/ ft- ${ }^{\circ} \mathrm{F}$-day

Density, $\mathrm{lb}_{\mathrm{m}} / \mathrm{ft}^{3}$

Total steam injection time, day

Thermal diffusivity, $\mathrm{ft}^{2} /$ day

Temperature at the interface between the reservoir and the cap or base rock, ${ }^{\circ} \mathrm{F}$

Porosity

Surface

Inside casing 


$\begin{array}{ll}\text { co } & \text { Outside tubing } \\ \mathrm{e} & \text { Formation } \\ \mathrm{f} & \text { Fluid } \\ \mathrm{i} & \text { Component } \\ \mathrm{inj} & \text { Injection } \\ \mathrm{r} & \text { Reference } \\ \mathrm{ti} & \text { Inside tubing } \\ \text { to } & \text { Outside tubing } \\ \mathrm{x} & \mathrm{x} \text {-direction }\end{array}$


ABSTRACT ...................................................................................

ACKNOWLEDGEMENTS ......................................................................

NOMENCLATURE............................................................................ vi

TABLE OF CONTENTS ..................................................................... ix

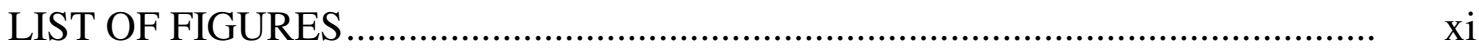

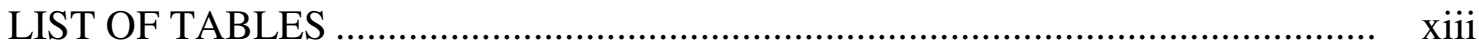

\section{CHAPTER}

I INTRODUCTION .............................................................. 1

II PROBLEM DESCRIPTION AND CALCULATING APPROACH... 5

Problem Description........................................................... 5

Selection of Calculating Approach and Limitation of Commercial

Software ................................................................ 7

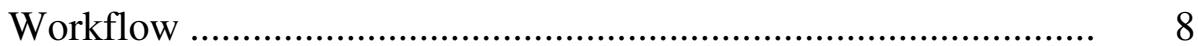

III RESERVOIR SIMULATION AND SENSITIVITY ANALYSIS ..... 10

Mathematical Formulation of Heat and Mass Transfer in the

Reservoir ............................................................................ 10

Heavy Oil Reservoir Review................................................ 15

Simulation Input ................................................................ 19

Sensitivity Parameters ............................................................ 25

Simulation Results................................................................ 26

IV CALCULATION OF WELLBORE TEMPERATURE ................... 34

Calculation of Heat Transfers in the Wellbore............................ 34

Temperature Profile of the Injection Well ................................ 36

Temperature Profile of the Production Well .............................. 41

V SURFACE OPERATIONS AND ECONOMIC CONSIDERATION. 43

Application of Geothermal Energy .......................................... 43

Surface Facilities for Heat Recovery Scheme ............................. 46

Estimation of Electricity Generated From Heat........................... 47

Case Example: Chena Hot Springs Field, Alaska ....................... 48

Economic Consideration ............................................................ 48 
CHAPTER $\quad$ Page

VI CONCLUSIONS AND RECOMMENDATIONS........................... 50

Conclusions …........................................................... 50

Recommendations .................................................... 52

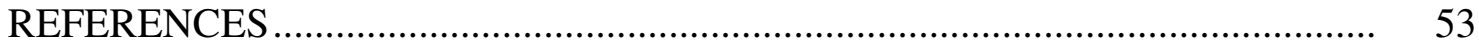

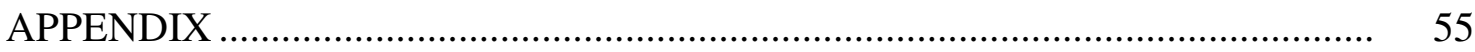

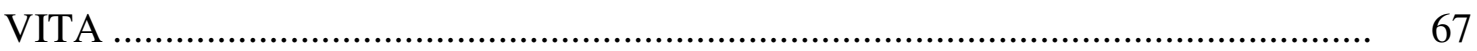




\section{LIST OF FIGURES}

FIGURE

Page

1 A proposed concept for recovering artificial geothermal energy for electricity production.

2 Heat recovery scheme for extracting heat from the artificial geothermal reservoir

3 Volume element for derivation of energy balance......

4 The model is a quarter of 5-spot inverted pattern, which is five acre per one completed pattern

$53 \mathrm{D}$ reservoir grid model showed locations of the injector and the producer

6 Viscosity profile of oil components

7 Relative permeability curves

8 The simulation of continuous steam injection is used to determine the abandonment point of the steamflooding process. For the base case scenario, abandonment of the steam injection phase is at 2,400 days, which is corresponds to water cut of $75 \%$ and SOR of 2.8. After this time, water is injected to extract heat from the artificial geothermal system.

9 Saturation distribution and temperature distribution of continuous steam injection

10 The energy profiles for the base case scenario indicate that approximately 41,000 MMBTU of cumulative energy could be recovered from the reservoir during 3,800 days of water injection. The average energy rate during this phase is approximately $11 \mathrm{MMBTU} /$ day.

11 The energy accumulated in the reservoir during the steamflooding could be recovered via water injection. Heat contribution from the overburden and underburden could support the energy recovery, as suggested by a decreasing cumulative heat loss over time.

12 Results of the sensitivity analysis

13 Time function in the Ramey equation

14 Temperature profile of the injection well during steamflooding process. The surface temperature is $590^{\circ} \mathrm{F}$ and the bottomhole temperature is $450^{\circ} \mathrm{F}$ 
15 Geothermal temperature near wellbore is raised as a result from heat dissipation to surrounding rock caused by steam injection

16 Volume of rock is heated depending on distance that heat could penetrate defined by moving thermal penetration thickness....................................

17 Geothermal temperature around the well and the temperature profile of water injection influenced by new geothermal energy...........................

18 Temperature profile of the production well during heat recovery phase. The average wellhead temperature of production fluid is obtained by integrating surface temperature profile divide by total production time....

19 Lindal diagram illustrate general temperature requirement of a spectrum of direct-use applications of geothermal energy but also ranges for electrical power generation

20 Heat recovery scheme for electrical power generation

21 Energy flow diagram describing fluid temperature and the electricity conversion in the system 


\section{LIST OF TABLES}

TABLE

Page

1 Oil classification based on fluid density, viscosity, and mobility............ 16

2 Properties used as a reference to build the based case model for this study 18

3 Grid properties assigned in the base case model.................................. 21

$4 \quad$ Properties of oil components .......................................................... 22

5 Range of variability for the parameters used in the sensitivity analysis, compared to the base case

6 Water injection begins when the abandonment criteria for the steam flooding process are reached. Water is then injected to recover energy until the economic cut-off .

7 Parameters used in calculation of temperature profile of the injection well

8 Parameters used in calculation of temperature profile of the production well .....

9 Parameters used for calculating electricity generation. 


\section{CHAPTER I}

\section{INTRODUCTION}

Large quantities of heavy oil and tar sands become attractive to the industry nowadays as the world's conventional oil production starts to decline. Another reason is that the heavy oil resources are abundant. In fact, approximately $70 \%$ of total world oil resources are from heavy oil, extra heavy oil, tar sand, and bitumen reservoirs.

To obtain production from heavy oil reservoirs, thermal methods are typically implemented in many heavy oil fields. These involve heating reservoir fluid to reduce its viscosity. Methods for thermal recovery include steam-assisted gravity drainage (SAGD), in-situ combustion, and cyclic steam stimulation (CSS). The most effective methods are steamflooding and hot waterflooding; recovery factors are additionally increased 20 to $30 \%$ by these two techniques.

Heavy oil reservoirs where steamflood or hot waterflood processes have been applied for a long time reach economic cutoffs resulting from high water cut, high steam-to-oil ratio (SOR), or steam breakthrough. Reservoirs are then either produced until depleted or abandoned. However, as a result of thermal processes, heat is still stored in reservoir rock and will gradually dissipate to overburden and underburden. This intrinsic value from thermal processes could be exploited in the form of geothermal energy potential.

Recent research has investigated uses of energy from hot fluids produced from heavy oil reservoirs subject to thermal processes. Teodoriu et al. (2007) proposed a novel concept for heat recovery that improves heavy oil production and simultaneously generates electricity. They focused on the heavy oil fields where hot waterflooding has been applied. Once the water cut reaches uneconomic values, production wells are normally

This thesis follows the style of SPE Journal. 
shut in or converted into injectors. The Teodoriu et al. concept is to use the heat from hot water production after water breakthrough to generate electricity. By injecting hot water into the reservoir (using conventional heaters and low-temperature solar heaters) and letting the water receive further heat from the reservoir itself (following thermal recovery operations), it is possible to recover significant amounts of thermal energy.

Fig.1 illustrates a proposed schematic of heat recovery for the electric power producing process. Synthetic reservoir models from their study showed that the reservoirs can constantly supply the heat to surface. However, their proposed concept needs to be verified by an assessment of the entire heat recovery system.

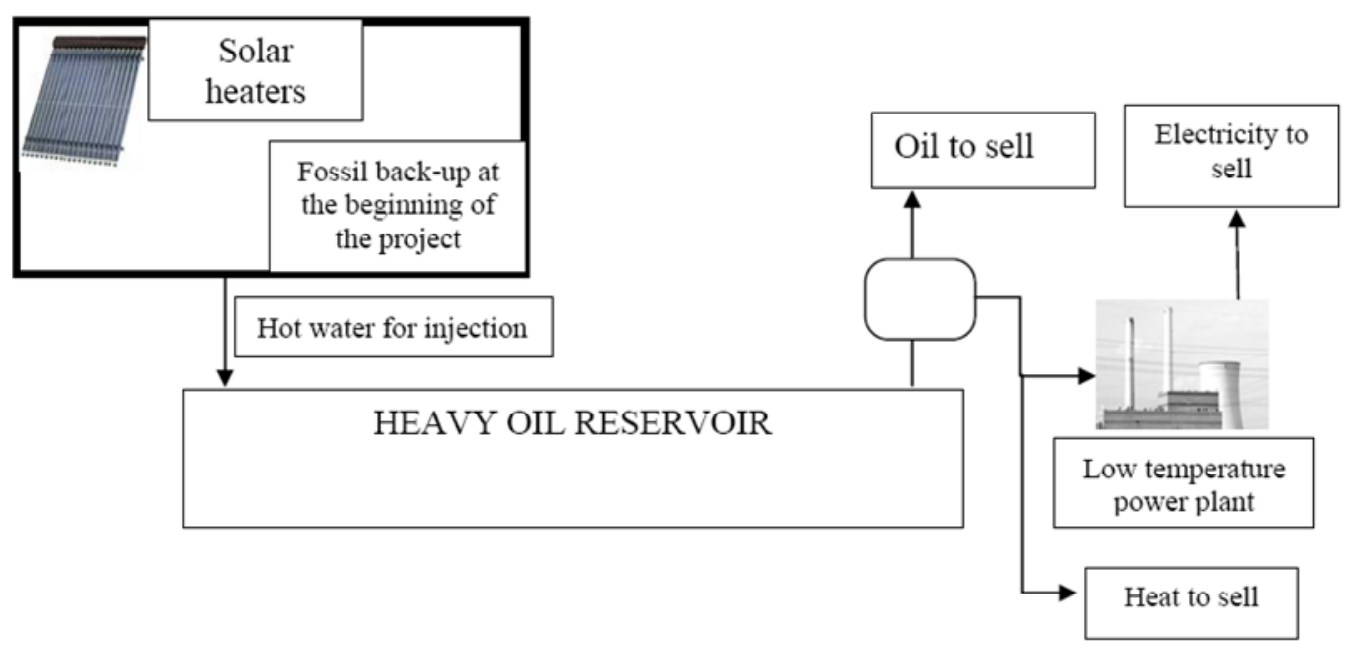

Fig. 1 - A proposed concept for recovering artificial geothermal energy for electricity production (Teodoriu et al. 2007).

Other studies have focused on the possibility of using the energy left in reservoirs that have been or will be abandoned. Zhang and Yuan (2008) indicate that energy left in a light oil reservoir could be recovered by oxidizing residual oil with injected air so that the reservoir can be transformed into an exceptional enhanced geothermal system (EEGS) with high temperature. Hot produced fluid from the EEGS could be used to 
generate power by using geothermal power generation technology. Valbuena et al. (2009) showed that hot produced fluid may be used for secondary heat recovery schemes, since it carries around $20 \%$ of energy from the steam injection process.

The objective of this project is to follow up the study initiated by Teodoriu et al. (2007) and extend the concept of harnessing geothermal energy from heavy oil fields that have undergone steamflooding. Such fields are good candidates for the heat recovery concept because the reservoir rock can accumulate substantial heat from steam injection, compared to fields that have undergone hot water flooding. Once the steamflooding process reaches economic cut-off resulting from high water cut and/or high SOR, the reservoir would be abandoned, leaving behind stored energy in the form of heat. From this point, the reservoir could be regarded as an artificial geothermal system and its intrinsic heat from the steamflooding stage recovered by water circulation, as proposed by Teodoriu et al.

We will perform the energy investigation in the heat recovery system including the water injection well, the artificial geothermal reservoir, the production well, and surface operations, and include economic consideration in this study.

Heat transfer within the reservoir, including heat loss rate to overburden and underburden, could be estimated using a numerical reservoir simulator with the compositional and thermal options. The simulator adopted for this study allows characterization of the fluid properties by an equation of state, as a function of pressure and temperature in each numerical grid. The energy balance equation and the continuity equation (conservation of mass equation) are solved iteratively in each grid block to obtain heat and mass flux rate from one block to another in every time step. In addition, heat transfer to base and cap rock is evaluated in the study. Heat that once dissipated to overburden and underburden as a result of stemflooding process transfer back to the reservoir, thus increasing reservoir energy (Chase and O'Dell 1973; Vinsome and Westerveld 1980; Weinstein 1972). 
We will also conduct sensitivity analyses of reservoir parameters and injecting parameters, which affect heat recovery from the artificial geothermal reservoir. The result from the sensitivity analysis can be used as a screening tool for selecting heavy oil reservoirs that could be extended their field life for the heat recovery process. Parameters in this study obtained from the literature of well-known heavy oil fields would cover possible variability ranges for the properties of the typical heavy oil data.

Wellbore heat transmission takes place when there is a difference between fluid and geothermal temperature (Ramey 1962). During steamflooding, steam heat losses cause fluid to condense into water phase. As a consequence, the surrounding rock would store heat in form of enthalpy increasing its temperature. In addition, excessive heat losses would increase the chance of cement bond failure and steam channeling behind pipe in the case of an improper completion design of the injection well (Castrup 2001). During the heat recovery phase using water injection, on the other hand, the surrounding rock would warm the wellbore injecting fluid. The temperature reversal effect in the injection well similar to what is happening in the reservoir heat losses to overburden could raise fluid temperature. Therefore, the solar heater as proposed in Teodoriu et al. concept might become unnecessary. Beside an estimation of the heat transmission in injection wells, we will calculate heat loss in the production wells quantify the amount of heat recovered at surface.

There are two ways of utilizing the produced heat from geothermal resources, direct-uses and electricity generations. Direct uses of geothermal resources apply widely in agriculture and district heating. The electricity generation conventionally requires high enthalpy resources (More than $150^{\circ} \mathrm{C}$ ) to power turbines. However, recent development offer utilization of low enthalpy resources to generate electrical power (Gupta and Roy 2007), which could be applied for low enthalpy resources. Amount of electrical power will be used to justify the feasibility of the project as originally proposed by Teodoriu et al. (2007). 


\section{CHAPTER II}

\section{PROBLEM DESCRIPTION AND CALCULATING APPROACH}

\section{Problem Description}

We will focus on heavy oil fields undergone the steamflood. Flooding pattern in this primary proof of concept is an inverted 5-spot injection with vertical drilling. This pattern offers the highest recovery factor among other pattern (Ziegler 1987). We assume necessary precaution of formation integrity has been preformed. Moreover, injection wells are assumed to be effectively insulated to reduce significant heat loss problem during steam injection.

Steamflooding is implemented until reaching economics limits, which are typically related to high operating cost. Economics cutoff point is determined by monitoring water cut and steam-to-oil ratio (SOR) of the field. It is needed to monitor production performance of producers to avoid steam break through. After steamflood process, if there is no further EOR method or the reservoir is further produced naturally until completely depleted, the reservoir would be abandoned leaving heat to be stored in the reservoir rock, but also residual oil that is unable to recover during steamflooding.

From that point onwards, the reservoir is regard as the artificial geothermal reservoir. We will employ heat recovery phase by injecting water to extract heat from the reservoir rock. We will start injecting water into the existing injection wells using surface pumps. For production wells, downhole pump will be installed to lift produced water to surface. Then, produced fluid from the wellhead will transport to the electricity generating device before flowing to the separator. Then, water will be re-circulated back to the injection wells again. The process will be repeated until it reaches the economic cutoff of the heat recovery scheme. 
We will investigate heat recovery of the artificial geothermal reservoir. Initially, water flowing downward the injection well is warmed up by the surrounding formation, in which it energy is accumulated from steam heat losses. Water is then received more heat from the reservoir rock and the adjacent formation. waterflooding front also sweep the subsequent residual oil that is not recovered during steamflooding process owing to too early termination of the oil recovery phase. Produced fluid, on the other hand, losing its energy within the wellbore before arriving surface. Then, the produced fluid is transported to either electricity-generating apparatus or direct-uses appliances. The water is then treated before re-circulating to the reservoir.

To follow up the purpose by Teodoriu et al., revenue from heat recovery will consider only by selling electricity to market. Additional revenue obtained from selling oil will be excluded from our analysis.

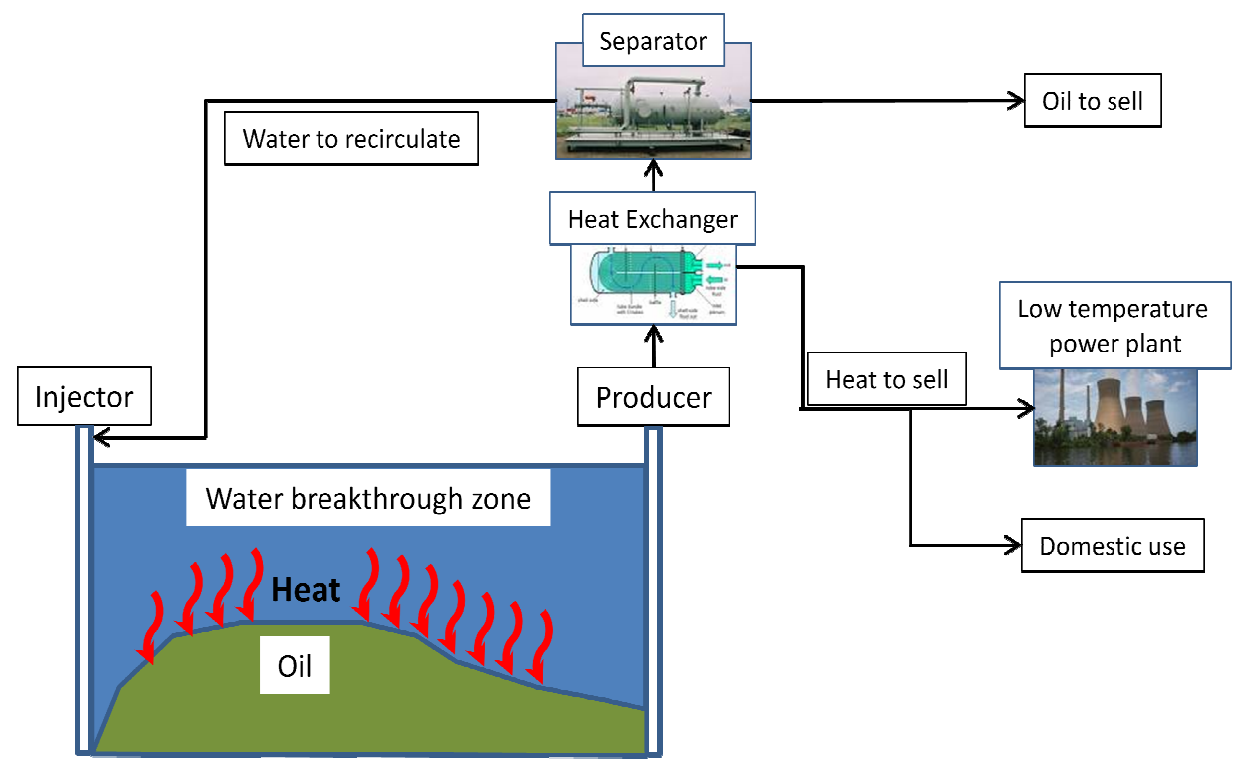

Fig. 2 Heat recovery scheme for extracting heat from the artificial geothermal reservoir (Teodoriu et al. 2007) 


\section{Selection of Calculating Approach and Limitation of Commercial Software}

In this study, the approach to calculate heat balance of the integrated production system that includes the injector, the producer, and the reservoir requires commercial software package that can resolve heat and mass transfer equation in the reservoir and the wells simultaneously. For the heavy oil fluid where thermal process is normally applied, solving of mass and heat flow within the reservoir demands a numerical reservoir simulator with compositional and thermal features. Fluid properties are characterized by an equation of state as a function of pressure and temperature in each numerical reservoir grids. The same characterization of the fluid properties should be applied in flow in the well to avoid an inconsistency problem.

Two combinations of the commercial reservoir simulator and wellbore modeling software were investigated to come up with the best approach for our research. ECLIPSE 300 Thermal option, Schlumberger Geoquest coupled with Reveal module, Petroleum Expert Ltd suite was selected for testing firstly. It appeared that when we transferred data file from ECLIPSE 300 Thermal option into Reveal software, composition of fluid and its properties must be propagated again. There also were inconsistencies between the way that ECLIPSE 300 Thermal option models fluid properties and the way Reveal does. Additionally, calculated enthalpy parameters could not be passed on from ECLIPSE 300 Thermal option to Reveal module. Therefore, it was decided not to use this combination of software in this study.

Second, Avocet IPM, Schlumberger, which couples ECLIPSE 300 Thermal option and PIPESIM, Schlumberger, was also evaluated. The problem in characterizing fluid properties in a wellbore simulator, PIPESIM, was that it requires the third party license call "Multiflash" in handling the compositional feature. This additional module was not available in our department. Moreover, software integration by Avocet is not directly suitable in our specific problem because careful fine-tuning to prevent convergence problems is required referred to our meeting with Schlumberger representatives. It is; however, suggesting investigating a further possibility to use the Avocet for this concept 
in order to combine a numerical reservoir simulator, a wellbore simulator, and a power plant simulator.

Third, the approach in this study was changed to separate calculation into two steps. The first step, heat and mass balance in the reservoir was calculated by ECLIPSE 300 Thermal option assuming constant injection well controls. Then, heat loss in wellbore was calculated by Prosper software, Petroleum Expert package suite, using result from ECLIPSE 300 Thermal option. Series of bottomhole temperature data is extracted and used as input for the wellbore simulator. Heat balance calculation in the production well was achievable in Prosper. However, calculating surface temperature of the injection well using a fixed node from the bottom hole is prohibited by software setting. Hence, we decided not to use this approach for our research because of its infeasibility.

Our method for determining heat and mass balance in this integrated production system is as follows. To begin with, we solve for heat recovery from the reservoir using the ECLIPSE 300 Thermal option simulator. Then, we calculate temperature profile of both injection and production wells using semianalytical equation to solve for wellhead fluid temperature. Discrete numbers of bottomhole temperature from the Eclipse simulator are extracted to use as input parameters for calculating heat transmission within the wellbore. By using this approach, it would prevent continuous calculation of energy transfer between the reservoir and the wells with regardless of time. Therefore, a simulator that can simultaneously solve energy balance in reservoir and wellbore would be recommended for improving the research result.

\section{Workflow}

1. Literature searches about classical heavy oil fields to be used for the sensitivity study.

2. Generate the synthetic reservoir model using properties from the fourth SPE comparative case. 
3. Simulate the heat and volumetric flow profiles during the steamflooding process to estimate volumetric and heat flow rate during the steamflood process.

4. Determine the start up for water injection, which is after steamflooding is no longer economic establishing as the beginning of the heat recovery process.

5. Run the reservoir simulator to quantify net energy rate, heat extraction from reservoir rock, and heat gain from adjacent formation during water injection phase.

6. Determine the abandonment time of water injection after heat recovery is no longer, meaning that the power requirement to run this heat recovery scheme is greater than the amount of heat recovered.

7. Conduct sensitivity analyses of reservoir parameters and injection parameters on heat recovery. Identify possible variability ranges based on literature data of classical heavy oil fields.

8. Determine the formation temperature around the injection well as a result of the steam injection process. Use new formation temperature to generate temperature profile of the injection well during the water injection phase.

9. If the bottomhole temperature of the injection well is not significantly affected by the new geothermal temperature, resulting in too much temperature deviation from the initial value assigned in the base case reservoir model, go to Step 10. Or else, use the new bottomhole temperature to generate the base case simulation.

10. Construct a temperature profile of the production well using bottomhole temperature as a starting point to determine fluid temperature arriving at wellhead. This is estimated by discretizing the bottomhole temperature output from the reservoir simulation and estimate the fluid temperature at surface.

11. Quantify electrical power generated form thermal produced fluid.

12. Estimate power consumption for heat recovery scheme.

13. Perform economic analysis to consider feasibility of this project. 
CHAPTER III

\section{RESERVOIR SIMULATION AND SENSITIVITY ANALYSIS *}

\section{Mathematical Formulation of Heat and Mass Transfer in the Reservoir}

Introducing heat to the reservoir increases the internal energy of both porous rock and fluid where hot fluid flows through the reservoir. Mostly, heat is transferred in the porous medium by conductive and convective mechanism.

In this study, we are focusing on the heat balance happened in the petroleum production system. We will use the commercial reservoir simulator to solve the flow equations numerically and compositionally. Therefore, understanding of the relationship of heat transfer, heat loss, and continuity equation is required. We will describe the basic knowledge about the heat balance, which follows the first law of thermodynamics, and the mass balance, which describe the conservation of mass.

Prats (1982) provide a description of the heat transfer mechanisms taking place in the reservoir as follows.

Heat conduction mechanism is the process by which heat is transferred through nonflowing materials by molecular collisions from a region of high temperature to a region of lower temperature. Solid, for example reservoir rock, is thermally more conductive than liquid phase such as oil and water. The law of heat conduction, known as Fourier's law, can be expressed as:

$$
u_{\lambda x}=-\lambda \frac{\partial T}{\partial x}
$$

* Part of this chapter is reprinted with permission from "Artificial Geothermal Energy Potential of Steam-Flooded Heavy Oil Reservoirs" by Limpasurat et al., 2010. The Int. J. Oil, Gas and Coal Technology, Volume 4, Copyright [2010] by Inderscience Enterprises Limited (awaiting publication in 2011). 
Heat convection mechanism is the process by which heat is carried passively by a fluid motion. The heat flux caused by convection is usually expressed as:

$$
u_{T}=q \rho C\left(T-T_{r}\right)
$$

Usually, the convective heat transfer is expressed as the convective energy flux, which represents total energy of the fluid combining potential and kinetic energy contribution with the enthalpy of the materials

$$
u_{T}=q \rho\left(h+\frac{g z}{J g_{c}}+\frac{q^{2}}{2 \phi^{2} J g_{c}}\right)
$$

The contribution of potential energy to the total energy is typically small when the fluid flows horizontally. Moreover, the contribution of kinetic energy to the energy balance of the reservoir is practically negligible. Therefore, combining the conductive and convective components and neglecting radiation heat transfer component results in the total energy flux caused by flow of flow in the $\mathrm{x}$ direction is expressed as:

$$
\begin{aligned}
u_{e, x} & =u_{\lambda, x}+u_{T, x} \\
& =-\lambda \frac{\partial T}{\partial x}+q_{x} \rho_{f} h_{f}
\end{aligned}
$$

The total energy fluxes in the $\mathrm{y}$ and $\mathrm{z}$ direction are also expressed as:

$$
\begin{aligned}
& u_{e, y}=-\lambda \frac{\partial T}{\partial y}+q_{y} \rho_{f} h_{f} \\
& u_{e, z}=-\lambda \frac{\partial T}{\partial z}+q_{z} \rho_{f}\left(h_{f}+\frac{g z}{J g_{c}}\right)
\end{aligned}
$$

Heat transfer for a control volume follows the first law of thermodynamics, which states that the total energy of a system is conserved, and therefore, the only way that the amount of energy in a system can change is if the energy crosses its boundaries:

Net energy transfer + Energy input from sources $=$ Gain in internal energy 


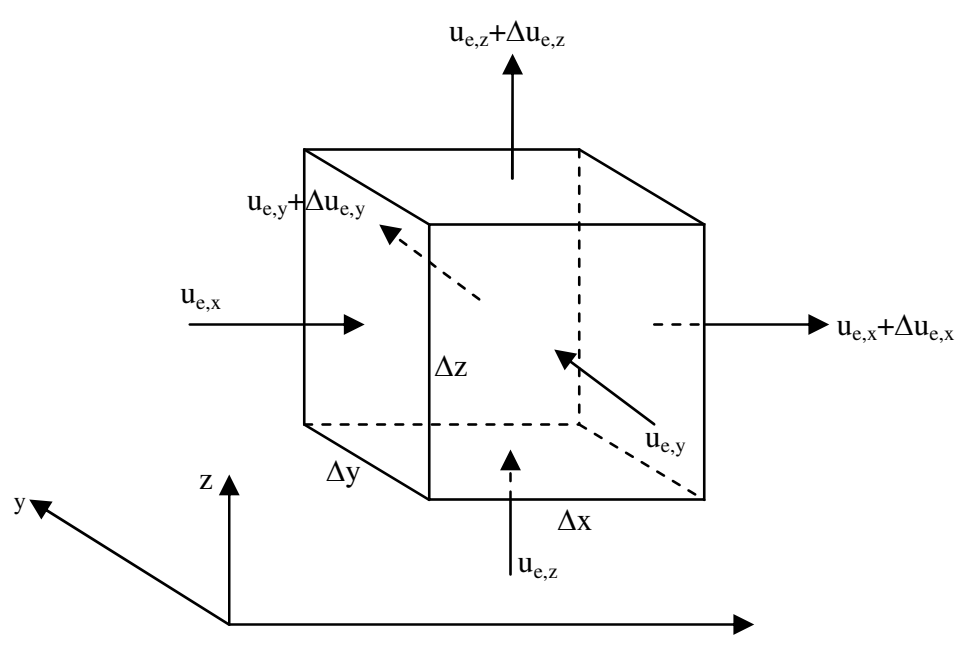

Fig. 3 Volume element for derivation of energy balance

Considering the stationary rectangular parallelpiped using a Cartesian coordinate system as shown in Fig. 3, the energy is transferred across each of the six faces. The total energy transferred into the volume element across the area $\Delta y \Delta z$ over a period of time $\Delta \mathrm{t}$ is $\mathrm{u}_{\mathrm{e}, \mathrm{x}} \Delta \mathrm{y} \Delta \mathrm{z} \Delta \mathrm{t}$, and the total energy transferred out of the volume element across the opposite face is $\left(\mathrm{u}_{\mathrm{e}, \mathrm{x}}+\Delta \mathrm{u}_{\mathrm{e}, \mathrm{x}}\right) \Delta \mathrm{y} \Delta \mathrm{z} \Delta \mathrm{t}$. The net energy transferred to the volume element is obtained by adding the contributions parallel to three coordinate axes.

Net energy transfer

$$
\begin{aligned}
&=\left(u_{e, x} \Delta y \Delta z\right.\left.+u_{e, y} \Delta x \Delta z+u_{e, z} \Delta x \Delta y\right) \Delta t \\
&-\left[\left(u_{e, x}+\Delta u_{e, x}\right) \Delta y \Delta z\right. \\
&+\left(u_{e, y}+\Delta u_{e, y}\right) \Delta x \Delta z \\
&\left.+\left(u_{e, z}+\Delta u_{e, z}\right) \Delta x \Delta y\right] \Delta t \\
&=-\left(\Delta u_{e, x} \Delta y \Delta z+\Delta u_{e, y} \Delta x \Delta z+\Delta u_{e, z} \Delta x \Delta y\right) \Delta t
\end{aligned}
$$

The rate of energy input from sources, per unit volume is $\dot{Q}$. Over the time period $\Delta \mathrm{t}$ and the volume element $\Delta \mathrm{x} \Delta \mathrm{y} \Delta \mathrm{z}$, the amount of energy from sources is expressed as:

$$
\text { Energy input from sources }=\dot{Q} \Delta x \Delta y \Delta z \Delta t
$$


The internal energy of the volume element at any time $\mathrm{t}$ is given by $\Delta e \Delta \mathrm{x} \Delta \mathrm{y} \Delta \mathrm{z}$. Since the volume element is stationary, the gain of internal energy within itself is independent of the space variables and is only a function of time. The internal energy at a time $t+\Delta t$ is $[\Delta e+(\Delta \rho)] \Delta \mathrm{x} \Delta \mathrm{y} \Delta \mathrm{z}$, and over the time period $\Delta \mathrm{t}$ :

$$
\text { Gain in internal energy }=\Delta(\rho e) \Delta x \Delta y \Delta z
$$

Substitution Eq.8, 9 and 10 into Eq.7 results in:

$$
\begin{aligned}
-\left(\Delta u_{e, x} \Delta y \Delta z\right. & \left.+\Delta u_{e, y} \Delta x \Delta z+\Delta u_{e, z} \Delta x \Delta y\right) \Delta t \\
& +\dot{Q} \Delta x \Delta y \Delta z \Delta t=\Delta(\rho e) \Delta x \Delta y \Delta z
\end{aligned}
$$

Dividing by $\Delta \mathrm{x} \Delta \mathrm{y} \Delta \mathrm{z} \Delta \mathrm{t}$ gives,

$$
-\left(\frac{\Delta u_{e, x}}{\Delta x}+\frac{\Delta u_{e, y}}{\Delta y}+\frac{\Delta u_{e, z}}{\Delta z}\right)+\dot{Q}=\frac{\Delta(\rho e)}{\Delta t}
$$

Taking limit as $\Delta \mathrm{x}, \Delta \mathrm{y}, \Delta \mathrm{z}$, and $\Delta \mathrm{t}$ approach zero result in the energy balance equation:

$$
\frac{\partial u_{e, x}}{\partial x}+\frac{\partial u_{e, y}}{\partial y}+\frac{\partial u_{e, z}}{\partial z}=-\frac{\partial(\rho e)}{\partial t}+\dot{Q}
$$

When $\mathrm{n}_{P}$ phase are presented, the internal energy per unit bulk volume $(\Delta e)$ is given by

$$
\rho e=(1-\phi) C_{e} \Delta T+\phi \sum_{i=1}^{n_{P}} S_{i} \rho_{i} e_{i}
$$

It should be noted that the total energy flux components in the $\mathrm{x}, \mathrm{y}$, and $\mathrm{z}$ directions are the sum of a conductive heat flux and the convective energy flexes for each flowing phase.

In the numerical reservoir simulator, heat loss model at the boundaries is required for estimate amount of heat transfer outside the control volume. Usually, we neglect the heat loss at the sides of the reservoir since it is much less than heat loss to the base and cap rock. Vinsome and Westerveld (1980) presented a method that can handle backflow of heat and cyclic temperature variations. Their semianalytical model is based on 
estimating the heat loss caused by one-dimensional linear heat conduction. The heat loss rate at the boundary surface is expressed as:

$$
-\left.\lambda \frac{d T}{d z}\right|_{z=0}=\lambda\left(\frac{\theta}{d}-p_{F}\right)
$$

The energy stored in the cap rock is expressed as:

$$
E_{c}=\frac{\lambda}{\alpha} \int_{0}^{\infty} T d z=\frac{\lambda}{\alpha} d\left(\theta+p_{F} d+2 q_{F} d^{2}\right)
$$

A mathematical description of particle flow in porous media is obtained from three principles: 1) Law of conservation of mass, 2) Law describing fluid transport such as Darcy's and Fick's laws, 3) Equation of state. For the first principle, the continuity equation states that:

Net mass transfer + Mass input from sources $=$ Accumulation of mass

For the compositional model where the fluid is composed of $\mathrm{n}$ components, flow of component $i$ in the control volume must follow the law of conservation of mass. The total mass flux component $i$ in the $\mathrm{x}$ direction is given by:

$$
w_{i, x}=\rho_{i} q_{i, x} \Delta y \Delta z
$$

We apply analogously the same approach to that that used in obtaining energy balance. The left term of the continuity equation for the component $i$ then becomes:

$$
\text { Net mass transfer }=-\nabla \cdot\left(\rho_{j} u_{m, j}\right)
$$

The mass sources of component $i$ per unit volume, corresponding to the middle term of the continuity equation is expressed as:

$$
\text { Mass input from sources }=w_{i}
$$

The accumulation term of component $i$ representing mass accumulated in the reservoir is expressed as: 


$$
\text { Accumulation of mass }=\frac{\partial\left(\rho_{i} \phi\right)}{\partial t}
$$

Substitute terms defined in Eq.19 through Eq.21 in Eq.17, the continuity equation of the mass component $i$ is expressed as:

$$
\nabla \cdot\left(\rho_{i} u_{m, i}\right)=-\frac{\partial\left(\rho_{i} \phi\right)}{\partial t}+w_{i}
$$

To demonstrate the diffusivity equation of component $i$ in a numerical grid, $u_{m, i}$ can be substituted by Darcy's law expressed as:

$$
\vec{u}_{m, i}=-\frac{k}{\mu_{i}} \nabla \Phi
$$

Also, the parameter $\rho_{\mathrm{i}}$ representing the fluid density of the component $i$ in Eq.22 can be solved by Peng-Robinson equation of state.

\section{Heavy Oil Reservoir Review}

One of the objectives in this research is to conduct the sensitivity study of the impact of the reservoir and injection parameters to the heat recovery scheme. This will be used for selection of heavy oil fields that could be potentially candidates for our proposed concept. Also, simulation results from the base case scenario will be used for the complete assessment of heat recovery system including the wellbore and surface operation. Literature about heavy oil will be used for generating our fictitious heavy oil reservoir.

Typically, heavy oil reservoirs occur from crude-oil source rocks with API gravity between $30^{\circ} \mathrm{API}$ and $40^{\circ} \mathrm{API}$. The oil becomes heavier only after substantial degradation during migration and after entrapment. The degradation can occur through a variety of biological, chemical, and physical processes. Heavy oil is geologically produced from young formations from the Pleistocene, Pliocene, and Miocene ages. These formations 
tend to be shallow and have less effective seals, exposing them to conditions that are conducive to forming heavy oils.

Heavy oil is an asphaltic, dense (low API gravity), and viscous oil that is chemically characterized by its content of asphaltene (very large molecules incorporating most of the sulfur and perhaps $90 \%$ of the metals in the oil). Although variously defined, the upper limit for heavy oil has been set at $22{ }^{\circ} \mathrm{API}$ gravity and a viscosity of $100 \mathrm{cp}$ (Meyer and Attanasi, 2003). Although density and viscosity are not directly linked, denser liquid hydrocarbons do tend to be more viscous. Table $\mathbf{1}$ summarizes the differences between light oil, heavy oil, extra heavy oil and tar sand/bitumen (Miller, 2008).

Table 1 Oil classification based on fluid density, viscosity, and mobility (after Miller, 2008)

\begin{tabular}{lccc}
\hline \multicolumn{1}{c}{ Type } & Density, ${ }^{\circ}$ API & Viscosity, $c p$ & Behavior at reservoir conditions \\
\hline Light Oil & $>22.7$ & $1-100$ & Mobile \\
Heavy Oil & $15-22.7$ & $100-1,000$ & Mobile \\
Extra Heavy Oil & $10-15$ & $1,000-10,000$ & Slightly Mobile \\
Tar Sand/ Bitumen & $7-12$ & $>10,000$ & Immobile \\
\hline
\end{tabular}

From literature, we have found some similarities in the properties of heavy oil reservoirs. For instance, heavy oil reservoirs are mostly located at shallow depth ranges around 1,000 ft. The porosity and the permeability are usually around 30\% and more than 1,000 md, respectively.

Large heavy oil reservoirs have been discovered in many regions. For example, in Canada, the recoverable heavy oil resources located in Alberta and Saskatchewan are estimated to be at least 50 to 60 billion bbl. Heavy oil qualities in the area range from 500 to $20,000 \mathrm{cp}$ in viscosity and densities are about $11^{\circ} \mathrm{API}$ to $18^{\circ} \mathrm{API}$. The Prudhoe Bay and Kuparuk fields, two of the largest conventional oil fields in Alaska, consist of heavy oil strata on top of the main producing zones. The estimated original oil in place 
(OOIP) is around 10 to 20 billion bbl, with the viscosities of the heavy oil ranging from 30 to $3,000 \mathrm{cp}$. Differences in geological systems in forming heavy oil reservoirs lead to variations in the reservoir properties in each location.

In order to build an analog reservoir model for this study, representative of real heavy oil reservoirs, we used the reservoir properties from three well-known heavy oil fields (Kern River, Duri and Faja Del Orinoco), together with those available in the public domain for the Fourth SPE Comparative Solution Project, problem 3 (Aziz et al. 1987).

\section{Kern River field}

Kern River field, located near Bakersfield, California, was discovered in 1899. The field is about 6 miles long and 4 miles wide, and has been producing heavy oil from the Miocene to the Pleistocene Age Kern River formation. The permeability ranges from 1 to 10 Darcy (Messner, 1990). The estimated OOIP is around 4 billion bbl. The oil viscosity of 500 to $10,000 \mathrm{cp}$, combined with low initial reservoir temperature and pressure, result in low primary recovery. Steamflooding was applied to enhance the recovery of this field. Lab experimental data show that viscosity of $12,000 \mathrm{cp}$ at reservoir temperature of $90^{\circ} \mathrm{F}$ is reduced to $20 \mathrm{cp}$ at the steam flood temperature of $260^{\circ} \mathrm{F}$ (Curtis et al., 2002). By 1973, $75 \%$ of Kern River production was from the steamflooding project. Typical steam injection is in a 5-spot pattern covering 2.5 acre in each pattern.

\section{Duri field}

Duri field, a large shallow heavy oil field in Indonesia, is the biggest steam flood operation in the world in term of oil production and volume of steam injected (Curtis et al., 2002). Primary production, mostly from solution-gas and compaction drives, peaked at 65,000 barrel of oil per day (BOPD) in the mid-1960s, which was only $7 \%$ recovery of the OOIP. Currently, the production is nearly 230,000 BOPD from the injection of $950,000 \mathrm{bbl}$ of cold water equivalent per day (BCWE/D) of steam with the ultimate

recovery factors expected to approach $70 \%$ in some areas. Steamflooding has been 
applied throughout the field, in which inverted 9-spot patterns over 15.5 acre are common. The production occurs mainly as a result of pressure generated by the steam before breakthrough into the production wells.

\section{Faja Del Orinoco field}

Faja Del Orinoco field, located in Venezuela, is one of the largest accumulations of heavy and ultra heavy oil (Curtis et al., 2002). The estimated OOIP is around 1.36 trillion bbl. Production started in 1998. The field was successfully implemented with multilateral wells draining the oil from the reservoir with not only the low formation pressure but also with the soft, highly stratified sand formation.

The reservoir properties of these three fields (Curtis et al., 2002; Hinkle, 2006; Messner, 1990) and those used in the Fourth SPE Comparative Solution Project (Aziz et al., 1987) are compared in Table 2.

Table 2 Properties used as a reference to build the based case model for this study

\begin{tabular}{|c|c|c|c|c|}
\hline Parameter & Kern River Field & Duri field & Faja del Orinoco & $\begin{array}{c}S P E \\
\text { comparative case }\end{array}$ \\
\hline Lithology & Sandstone & Sandstone & $\begin{array}{l}\text { Unconsolidated } \\
\text { sandstone }\end{array}$ & N/A \\
\hline Depth of top reservoir, $\mathrm{ft}$ & $300-850$ & 500 & $1,200-2,350$ & 1500 \\
\hline Formation thickness, $\mathrm{ft}$ & $50-100$ & 120 & $<360$ & 100 \\
\hline Porosity, \% & 31 & 34 & $30-35$ & 30 \\
\hline Permeability, md & $1,000-10,000$ & 1500 & $1,000-17,000$ & 1000 \\
\hline Water saturation, $\%$ & 50 & 53 & 36 & 45 \\
\hline Viscosity, cp & $500-10,000$ & 330 & $>5,000$ & 453 \\
\hline Density, ${ }^{\circ} \mathrm{API}$ & $10-15$ & 20 & $8.5-10$ & 14 \\
\hline $\begin{array}{l}\text { Initial reservoir pressure, } \\
\text { psia }\end{array}$ & 100 & 100 & $630-895$ & 75 \\
\hline $\begin{array}{l}\text { Initial reservoir } \\
\text { temperature, }{ }^{\circ} \mathrm{F}\end{array}$ & 90 & 100 & $100-135$ & 125 \\
\hline Rock compressibility, & 0.000735 & 0.000057 & $0.00008-0.00009$ & 0.0001 \\
\hline Reservoir area, acre & 2.5 (5-spot) & $\begin{array}{l}15.5 \text { (invert 9- } \\
\text { spot) }\end{array}$ & $\begin{array}{c}237 \text { (Multilateral } \\
\text { horizontal drilling) }\end{array}$ & 2.5 \\
\hline Steam temperature, ${ }^{\circ} \mathrm{F}$ & 260 & 450 & N/A & 450 \\
\hline
\end{tabular}




\section{Simulation Input}

The reservoir simulator used in this study is ECLIPSE 300 Thermal option Version 2008.1. It is a multi-component thermal simulator that could numerically solve nonisothermal reservoir conditions such as in steamflooding problem.

Our base case scenario was modeled using available data from the Fourth SPE Comparative Solution Project, problem 3 (Aziz et al., 1987). We assume that properties from this source have been extensively validated by the oil and gas community over years. Sensitivity analyze is performed to show the effects of various parameters on the geothermal energy recovery. Three well-known heavy oil fields from literature search were taken into account for assigning the possible variability of parameters used in the sensitivity study. When the range could not be found in the literature, the relevant parameter was arbitrarily altered by 10 to $40 \%$.

\section{Grid properties}

A Cartesian 3-dimensional model was constructed based on the inverted 5-spot pattern representing five acre of one complete pattern (Fig. 4). We simulated one quarter of that pattern discretizing to be in $15 \times 15 \times 10$ grid cells. For the base case scenario, the surface dimension of the model was 230 x 230 sq. ft. with $100 \mathrm{ft}$ in thickness. Fig. 5 presents the base case model, which showed the location of the well placement for one injector and one producer. 


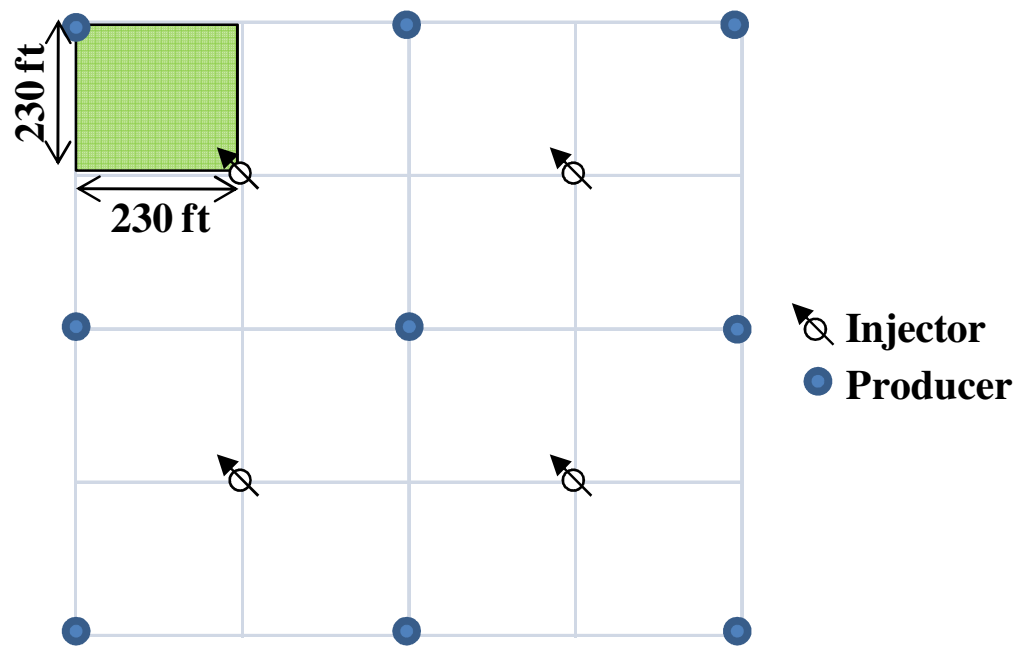

Fig. 4 The model is a quarter of 5-spot inverted pattern, which is five acre per one completed pattern

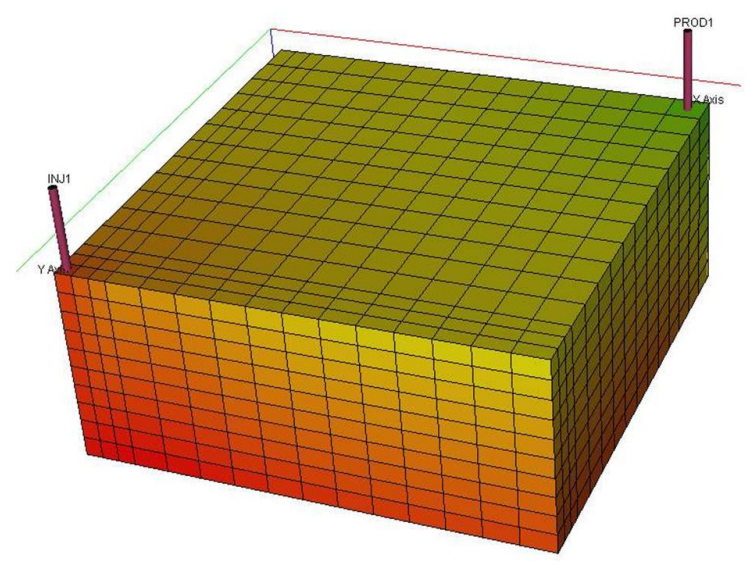

Fig. 5 3D reservoir grid model showed locations of the injector and the producer

The reservoir model was assumed to be sandstone located at 1,500 ft deep. Rock in each grid cell was assumed to have the isotropic and homogenous properties. Thermal properties including thermal conductivity and heat capacity of rock were also assumed to be homogeneous but different from the cap and the base rock. Table $\mathbf{3}$ summarizes grid properties used in the base case model. 
Table 3 Grid properties assigned in the based case model

\begin{tabular}{lr}
\hline Porosity, \% & Value \\
Horizontal permeability, md & 30 \\
Vertical permeability, md & 1500 \\
Rock compressibility, $\mathrm{psi}^{-1}$ & 0.0005 \\
Conductivity of caprock, BTU $/ \mathrm{ft} / \mathrm{day} /{ }^{\circ} \mathrm{F}$ & 24 \\
Heat capacity of caprock, BTU/ft $/{ }^{3} \mathrm{~F}$ & 35 \\
Conductivity of reservoir, BTU $/ \mathrm{ft} / \mathrm{day} /{ }^{\circ} \mathrm{F}$ & 23.4 \\
Heat capacity of reservoir, BTU/ft ${ }^{3} /{ }^{\circ} \mathrm{F}$ & 42.3 \\
\hline
\end{tabular}

\section{Fluid properties}

The compositional fluid was modeled in the thermal process has an impact stripping process of the light molecule from the heavier molecule. The light components, as a result from viscosity reduction, mixed with steam in the condensation front flows towards the production wells leaving heavier residue to be flooded by subsequent steam front.

The heavy oil used in this study is $14^{\circ} \mathrm{API}$ at standard conditions. The oil viscosity is $453 \mathrm{cp}$ at $125^{\circ} \mathrm{F}$ (Initial condition). To represent oil properties in compositional model, three pseudo components were propagated. Composition and fluid properties are shown in Table 4. The plots of viscosity versus temperature for each pseudo component is shown in Fig. 6. 
Table 4 Properties of oil components (After Aziz et al., 1987)

\begin{tabular}{lrrr}
\hline \multicolumn{1}{c}{ Parameter } & \multicolumn{3}{c}{ Component } \\
& \multicolumn{1}{c}{1} & \multicolumn{1}{c}{ } & \multicolumn{1}{c}{3} \\
\hline Initial composition & 0.5030 & 0.1614 & 0.3356 \\
Molecular weight & 250 & 450 & 600 \\
Specific heat capacity, & & & \\
$\mathrm{BTU} / \mathrm{lb}_{\mathrm{m}} /{ }^{\circ} \mathrm{F}$ & 0.53 & 0.55 & 0.6 \\
Density at standard condition, & & & \\
$\mathrm{lb}_{\mathrm{m}} / \mathrm{ft}^{3}$ & 52.3 & 57.64 & 61.2 \\
$\mathrm{Cr}^{3}$ itical pressure, $\mathrm{psia}$ & 225 & 140 & - \\
Critical temperature, $^{\circ} \mathrm{F}$ & 800 & 950 & - \\
\hline
\end{tabular}

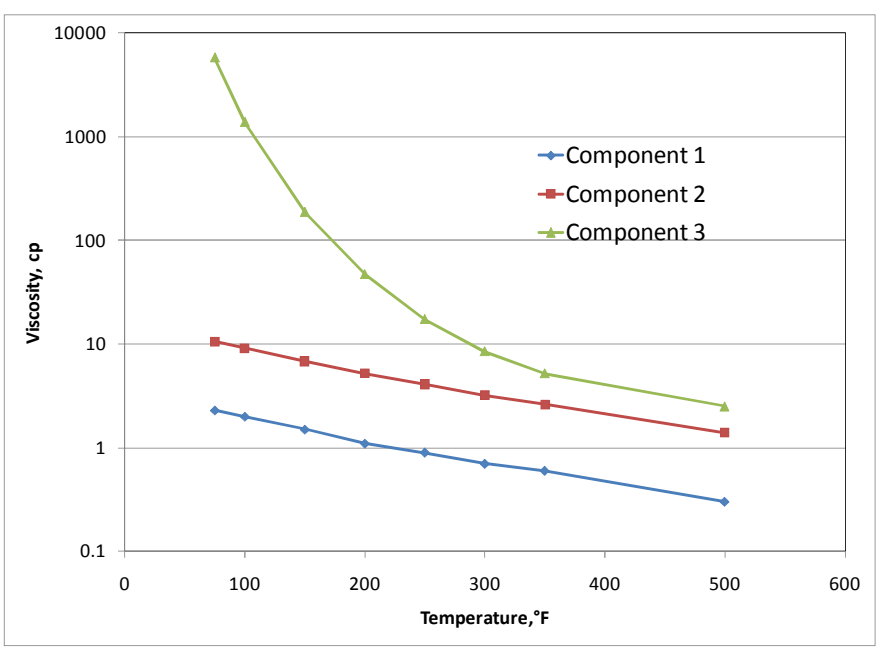

Fig. 6 Viscosity profile of oil components

Relative permeability is a measurement of effective permeability of one phase at certain saturation normalized by the absolute permeability (Goda and Behrenbruch 2004). It describes relative flow of one fluid phase compared to others in the reservoir. Temperature, flow velocity, saturation history, wettability changes and the mechanical and chemical behavior of the matrix material may all play roles in changing the functional dependence of the relative permeability on saturation. However, the relative 
permeability is believed to depend primarily on the volume occupied by a phase and so is expressed as a function of saturation. To find the best flow behavior of particular fluid of the reservoir, the relative permeability must be obtained as a part in special core analysis. When such circumstance becomes unavailable, which is likely in evaluating new reservoirs or in reservoir simulation studies, the Brook-and-Corey correlation are used to determine the relative permeability curve. This correlation is simply a power law model and is a function of relative permeability end-point; i.e., end-point relative permeability to oil at irreducible water saturation, and end-point relative permeability to water at residual oil saturation. The relative permeability data derived from the Brookand-Corey correlation are shown in Fig. 7. In this study, the capillary pressure is neglected. Note that, the effect of temperature on relative permeability was not modeled, in line with the dataset of the Fourth SPE Comparative Solution Project.
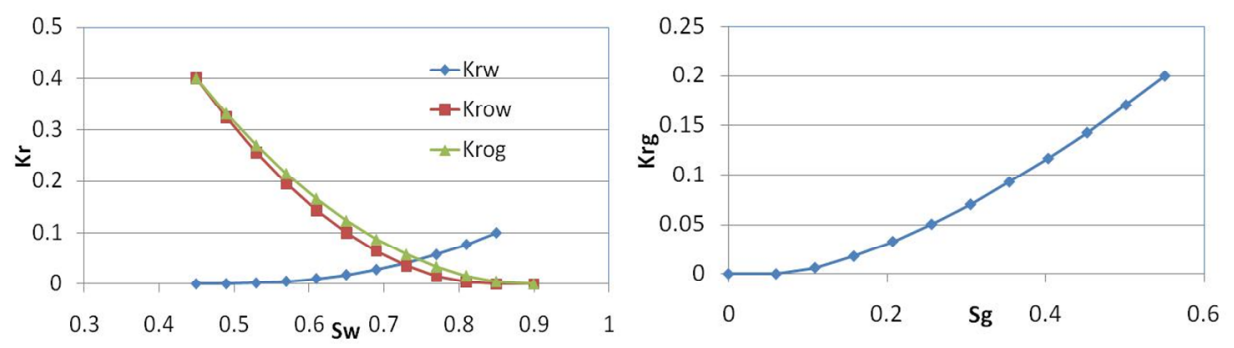

Fig. 7 Relative permeability curves

\section{Model initialization and project operations}

We assumed the initial water saturation is $45 \%$ in the reservoir. Neither aquifer nor initial gas cap were assigned to the reservoir model. The initial reservoir condition is 250 psia and $125^{\circ} \mathrm{F}$. The injection well and the production well are perforated for the full interval.

Production schedule were separated into two phases, the oil recovery phase and the heat recovery phase. During the oil recovery phase, the reservoir was constantly undergone 
by steamflooding from the beginning until reaching the economic cutoff point. For the base case scenario, we inject constant steam rate of $50 \mathrm{BBL} /$ day of cold water equivalent with $70 \%$ wet steam at $450^{\circ} \mathrm{F}$ downhole during the steamflooding process. We assumed that this steam condition can be applied continuously without well integrity problem in the case of unconsolidated sandstone. The producer was controlled with the bottomhole pressure of 100 psia, assuming that the artificial lift is implemented in within borehole, and the target rate is $70 \mathrm{BBL} /$ day.

The continuous steam injection is simulated to determine the abandonment point of the oil recovery phase. The economic cut-off of the steamflood process is determined at water cut of 75\% and high steam-to-oil ratio. Oil recovery and energy storage within the reservoir were estimated during this stage.

During the heat recovery phase, which is considered at the point where the steamflooding process is terminated onwards, water is immediately injected to the existing injector with $500 \mathrm{BBL} /$ day and $86^{\circ} \mathrm{F}\left(30^{\circ} \mathrm{C}\right)$. The producer is then controlled with the target rate of $250 \mathrm{BBL} /$ day and the same control bottomhole pressure as per the steamflooding phase.

The simulation then continues until the economic cut-off of the water injection phase is reached. For this preliminary proof of concept, it is assumed that the cut-off is reached when the net energy output from the reservoir is less than the total power required to inject the water downhole (assuming 50\% pump efficiency) and lift the produced fluids to the wellhead (Weatherford, 2006). The resulting energy cut-off value is 7 MMBTU/day. 


\section{Sensitivity Parameters}

Sensitivity analyses are performed to show the effects of various properties on the geothermal energy recovery. The amount of stored energy depends on the heat flux injected during steamflooding (function of steam temperature, steam injection rate and duration of the steam flood), but also on the thermal properties of reservoir fluids, reservoir rock, overburden and underburden. These have an impact on the overall heat transfer process, including heat accumulation and dissipation. Parameters shown in Table 5 were selected for our research. The variability ranges of each parameter were based on literature search. If there is no available source, the relevant parameters was arbitrarily altered by 10 to $40 \%$.

Table 5 Range of variability for the parameters used in the sensitivity analysis, compared to the base case.

\begin{tabular}{|c|c|c|c|}
\hline Parameter & Low & Base & High \\
\hline \multicolumn{4}{|l|}{ Geometry } \\
\hline Area, acres & 2.5 & 5 & 8 \\
\hline Thickness, ft & 50 & 100 & 300 \\
\hline \multicolumn{4}{|l|}{ Rock Property } \\
\hline Porosity, \% & 25 & 30 & 35 \\
\hline Permeability, md & 1,000 & 1,500 & 5,000 \\
\hline \multicolumn{4}{|l|}{ Rock thermal properties } \\
\hline $\begin{array}{l}\text { Conductivity of cap rock, } \\
\text { BTU } / \mathrm{ft} / \mathrm{day} /{ }^{\circ} \mathrm{F}\end{array}$ & 8.3 & 24 & - \\
\hline Heat capacity of reservoir, $\mathrm{BTU} / \mathrm{ft}^{3} /{ }^{\circ} \mathrm{F}$ & 36.0 & 42.3 & 48.6 \\
\hline \multicolumn{4}{|l|}{ Initial reservoir conditions } \\
\hline Temperature, ${ }^{\circ} \mathrm{F}$ & 90 & 125 & 160 \\
\hline Pressure, psi & 100 & 250 & 600 \\
\hline \multicolumn{4}{|l|}{ Steam injection } \\
\hline Rate, STBCWE/day & 25 & 50 & 100 \\
\hline Temperature, ${ }^{\circ} \mathrm{F}$ & 250 & 450 & 550 \\
\hline \multicolumn{4}{|l|}{ Water injection } \\
\hline Temperature, ${ }^{\circ} \mathrm{F}$ & 68 & 86 & 104 \\
\hline
\end{tabular}




\section{Simulation Results}

\section{Base case model}

Steam improves the displacing efficiency over that obtainable from a conventional waterflood because of viscosity reduction of the crude oil. The effect of viscosity reduction becomes obvious as more heat enters the formation.

To determine abandonment time of steamflooding, the case with continuous steam injection was simulated. Fig. 8 shows the oil production rate, recovery factor, water cut, and SOR profiles. The oil rate is maintained at $70 \mathrm{STB} /$ day for 600 day and then it declines with increasing water rate. The reservoir is considered to reach abandonment at 2,400 days, when the water cut and the SOR are $75 \%$ and 2.8 , respectively. At this stage, the oil recovery factor is $57 \%$. Steam breakthrough would occur at 3,000 day if steam injection were carried on.

Fig. 9 illustrates distribution of oil saturation and temperature within the reservoir. Steam condensation front movement is not piston-liked as clearly seen in the temperature distribution at 365 days. This is a result from gravity separation, in which steam and light components move upwards leaving heavier residue flow downward. The effect becomes more obvious by the increased density difference between light components and heavier component as more heat is introduced to the reservoir. Hence, residue oil at the bottommost of the reservoir can be recovered by horizontal infill drilling. 

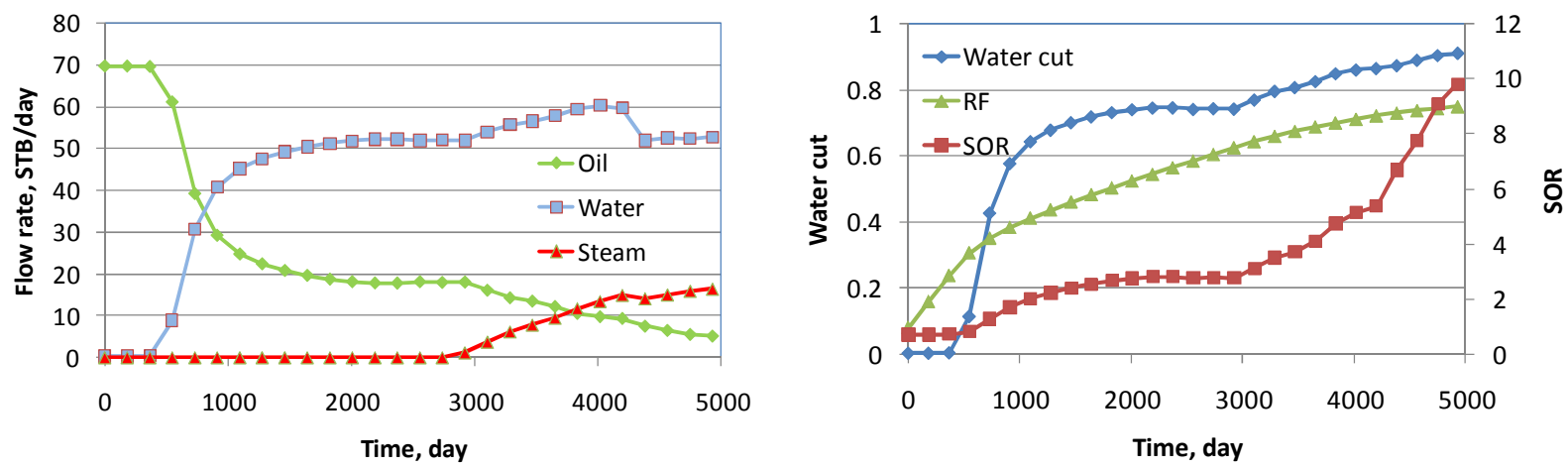

Fig. 8 The simulation of continuous steam injection is used to determine the abandonment point of the steamflooding process. For the base case scenario, abandonment of the steam injection phase is at 2,400 days, which corresponds to a water cut of $75 \%$ and an SOR of 2.8. After this time, water is injected to extract heat from the artificial geothermal system.

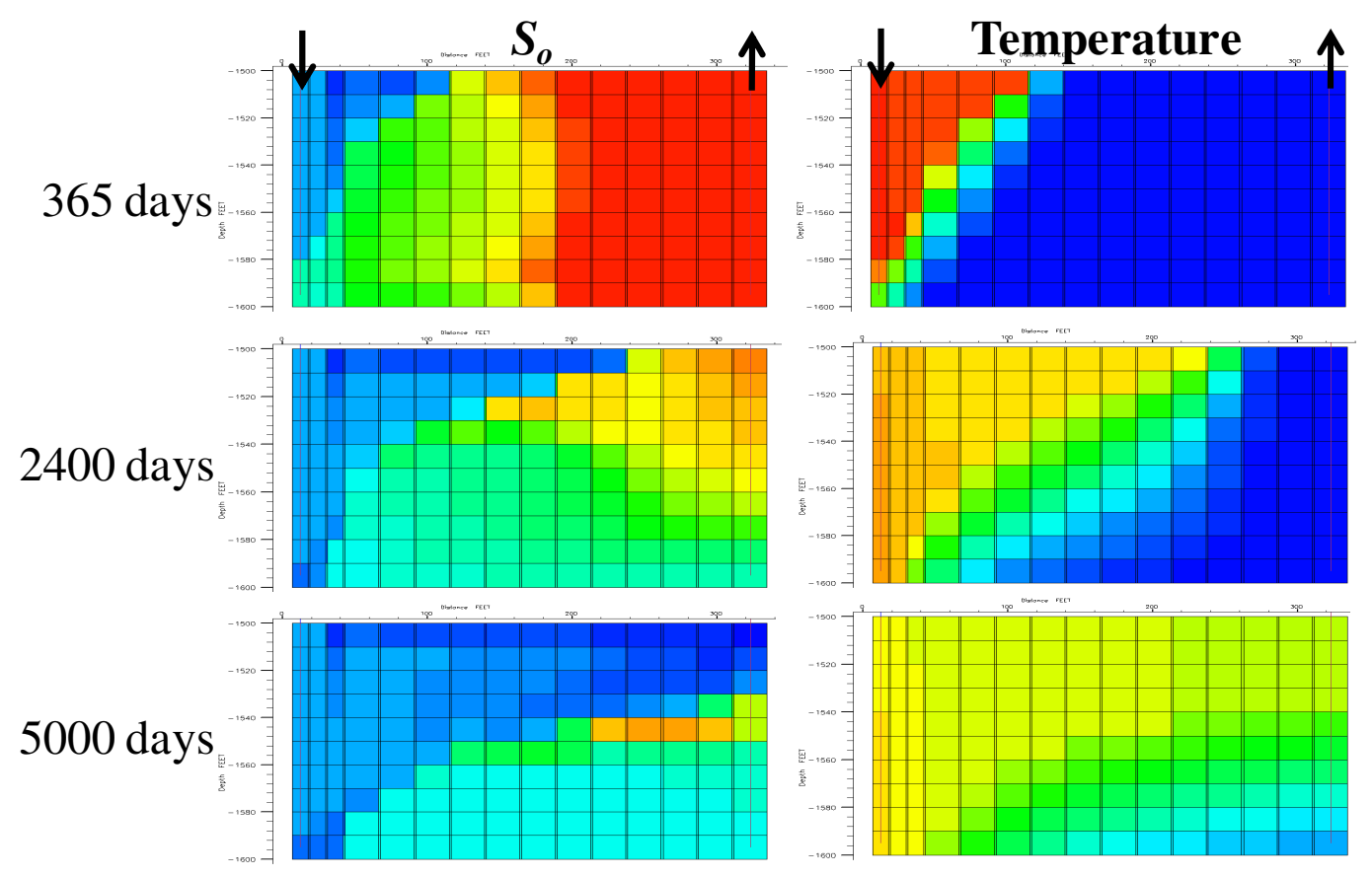

Fig. 9 Saturation distribution and temperature distribution of continuous steam injection

During steamflooding, steam heats up the reservoir. Heat is dissipated into reservoir fluid and rock, resulting in steam condensation in the reservoir. Heat is accumulated in the reservoir rock depending on the volumetric heat capacity of the formation. At the 
same time, heat is dissipated through the surrounding rock, which is at an initial lower temperature during steam injection.

As the temperature of the overburden and underburden increases during steamflooding, the surrounding rock supports the energy exchange to the water by transferring heat back to the reservoir formation during the water injection phase. As a result, the produced energy rate increases up to $15 \mathrm{MMBTU} /$ day and then gradually decreases as the energy in the reservoir decreases (Fig. 10). This trend reflects those of the energy accumulated in the reservoir formation and the energy loss to the base and cap rock: the cumulative energy accumulation in the reservoir and the cumulative energy loss to the adjacent formation decrease during the water injection phase, as shown in Fig. 11.

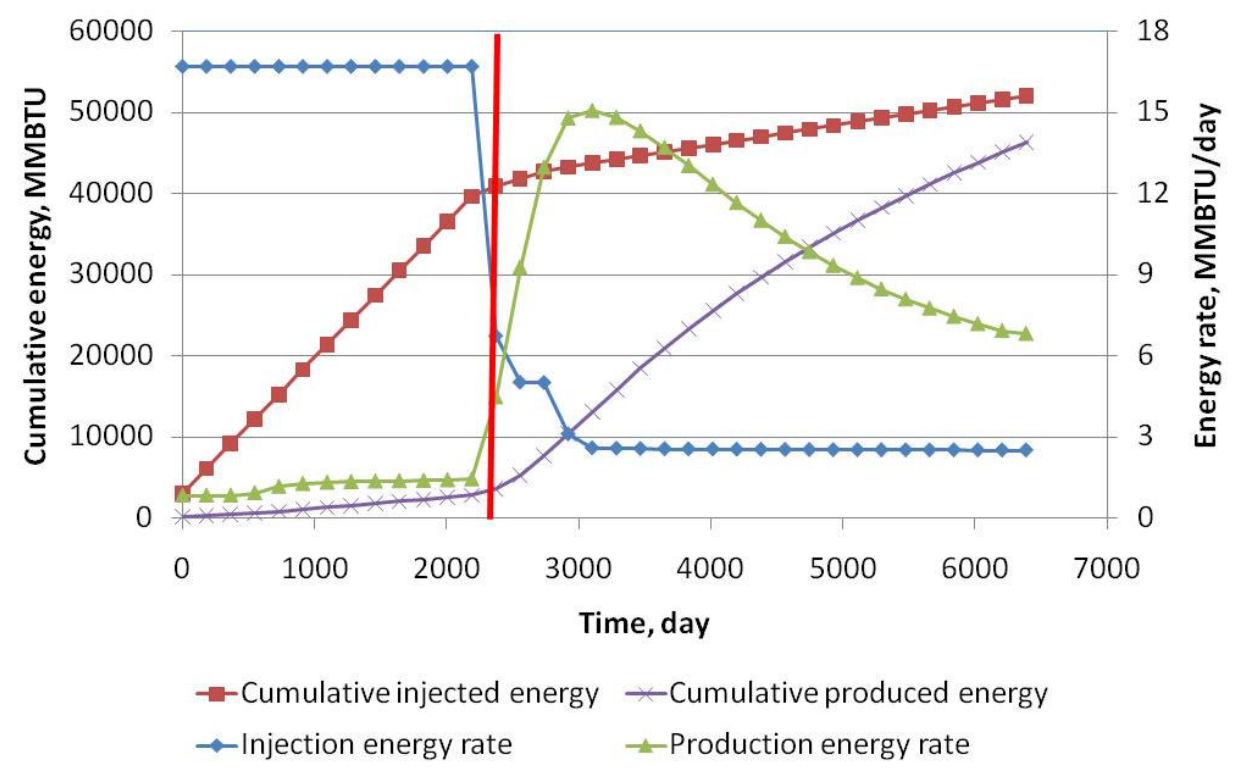

Fig. 10 The energy profiles for the base case scenario indicate that approximately 41,000 MMBTU of cumulative energy could be recovered from the reservoir during 3,800 days of water injection. The average energy rate during this phase is approximately 11 MMBTU/day. 


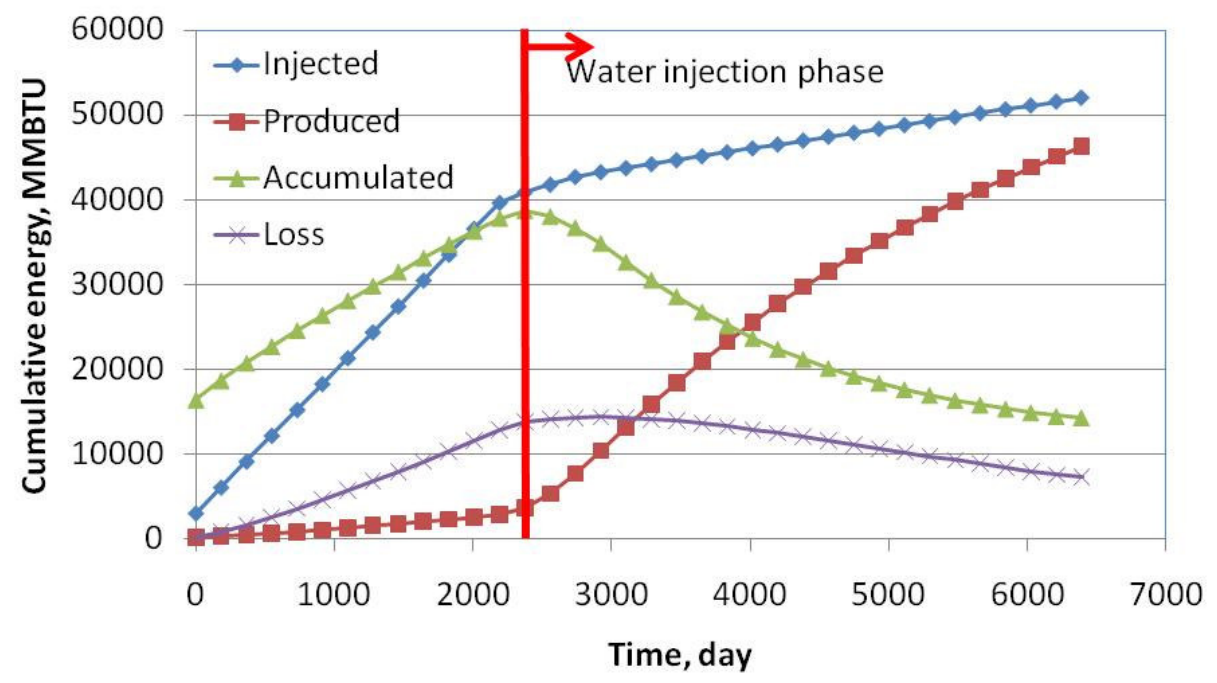

Fig. 11 The energy accumulated in the reservoir during the steamflooding could be recovered via water injection. Heat contribution from the overburden and underburden could support the energy recovery, as suggested by a decreasing cumulative heat loss over time.

The average produced energy rate during the water injection phase is approximately 11 MMBTU/day for 3,800 days. At the time of final abandonment, a cumulative net energy production of $3.02 \times 10^{4} \mathrm{MMBTU}$ is recovered. Net energy production is defined as the difference between cumulative produced energy and cumulative injected energy during the water injection phase $\left(\Delta \mathrm{E}_{\text {prod }}-\Delta \mathrm{E}_{\text {inj }}\right)$.

Additional $8 \%$ of oil in place is recovered during the water injection phase. Thus, it is possible that coproduction of heat and residue oil during the heat recovery phase can enhance economics of heavy oil projects after abandonment of conventional recovery processes. "Quaternary" recovery processes, as proposed by Teodoriu et al., will be further assesed in the financial aspect and investigated about applications of recovered heat.

It must be noted that our model only represents $1 / 4^{\text {th }}$ of an inverted five-spot pattern, so the results would have to be up-scaled to the real field scale; it is therefore expected that the field energy throughput could be 100 times greater. 


\section{Sensitivity parameter results}

Sensitivity analyses were carried out to compare the effect of various parameters on the heat recovered in terms of net energy produced. The variability ranges for the various sensitivity parameters follow the information provided in Table 5. The net energy produced from each sensitivity case is shown in Fig. 12. The simulation times and the average production energy rates for the various sensitivity analyses are summarized in Table 6. It is noted that, for the base case model, the net energy produced is $3.02 \times 10^{4}$ MMBTU over 3,800 days of water injection.

Table 6 Water injection begins when the abandonment criteria for the steamflooding process are reached. Water is then injected to recover energy until the economic cut-off.

\begin{tabular}{|c|c|c|c|c|c|}
\hline \multicolumn{2}{|l|}{ Sensitivity Case } & \multirow{2}{*}{$\begin{array}{l}\text { Beginning date } \\
\text { of water inj., day } \\
2,400\end{array}$} & \multirow{2}{*}{$\begin{array}{c}\begin{array}{c}\text { Abandonment } \\
\text { date, day }\end{array} \\
\mathbf{6 , 2 1 0}\end{array}$} & \multirow{2}{*}{$\begin{array}{c}\begin{array}{c}\text { Duration, } \\
\text { day }\end{array} \\
\mathbf{3 , 8 1 0}\end{array}$} & \multirow{2}{*}{$\begin{array}{c}\text { Energy production } \\
\text { rate, MMBTU/day }\end{array}$} \\
\hline Base case scenario & & & & & \\
\hline \multicolumn{6}{|l|}{ Geometry } \\
\hline \multirow[t]{2}{*}{ Area } & Low & 1,150 & 2,830 & 1,680 & 11.9 \\
\hline & High & 3,800 & 10,227 & 6,423 & 10.0 \\
\hline \multirow[t]{2}{*}{ Thickness } & Low & 950 & 2,738 & 1,788 & 9.1 \\
\hline & High & 7,100 & 17,592 & 10,492 & 12.1 \\
\hline \multicolumn{6}{|l|}{ Rock property } \\
\hline \multirow[t]{2}{*}{ Porosity } & Low & 1,700 & 4,992 & 3,292 & 9.6 \\
\hline & High & 3,200 & 7,579 & 4,379 & 12.0 \\
\hline \multirow[t]{2}{*}{ Permeability } & Low & 1,950 & 5,418 & 3,468 & 10.0 \\
\hline & High & 2,400 & 6,269 & 3,869 & 10.7 \\
\hline \multicolumn{6}{|l|}{ Rock thermal properties } \\
\hline Conductivity of caprock & Low & 2,500 & 6,118 & 3,618 & 12.4 \\
\hline \multirow[t]{2}{*}{ Heat capacity of reservoir } & Low & 3,000 & 6,940 & 3,940 & 12.0 \\
\hline & High & 2,200 & 6,269 & 4,069 & 10.2 \\
\hline \multicolumn{6}{|l|}{ Initial reservoir conditions } \\
\hline \multirow[t]{2}{*}{ Temperature } & Low & 1,950 & 4,261 & 2,311 & 8.7 \\
\hline & High & 2,450 & 7,396 & 4,946 & 11.9 \\
\hline \multirow[t]{2}{*}{ Pressure } & Low & 2,700 & 6,726 & 4,026 & 11.4 \\
\hline & High & 2,200 & 5,904 & 3,704 & 10.1 \\
\hline \multicolumn{6}{|l|}{ Steam injection } \\
\hline \multirow[t]{2}{*}{ Rate } & Low & 4,950 & 8,644 & 3,694 & 10.4 \\
\hline & High & 1,100 & 4,992 & 3,892 & 10.6 \\
\hline \multirow[t]{2}{*}{ Temperature } & Low & 2,100 & 5,479 & 3,379 & 9.9 \\
\hline & High & 2,900 & 7,365 & 4,465 & 11.8 \\
\hline \multicolumn{6}{|l|}{ Water injection } \\
\hline \multirow[t]{2}{*}{ Temperature } & Low & 2,400 & 5,783 & 3,383 & 10.9 \\
\hline & High & 2,400 & 7,060 & 4,660 & 10.5 \\
\hline
\end{tabular}




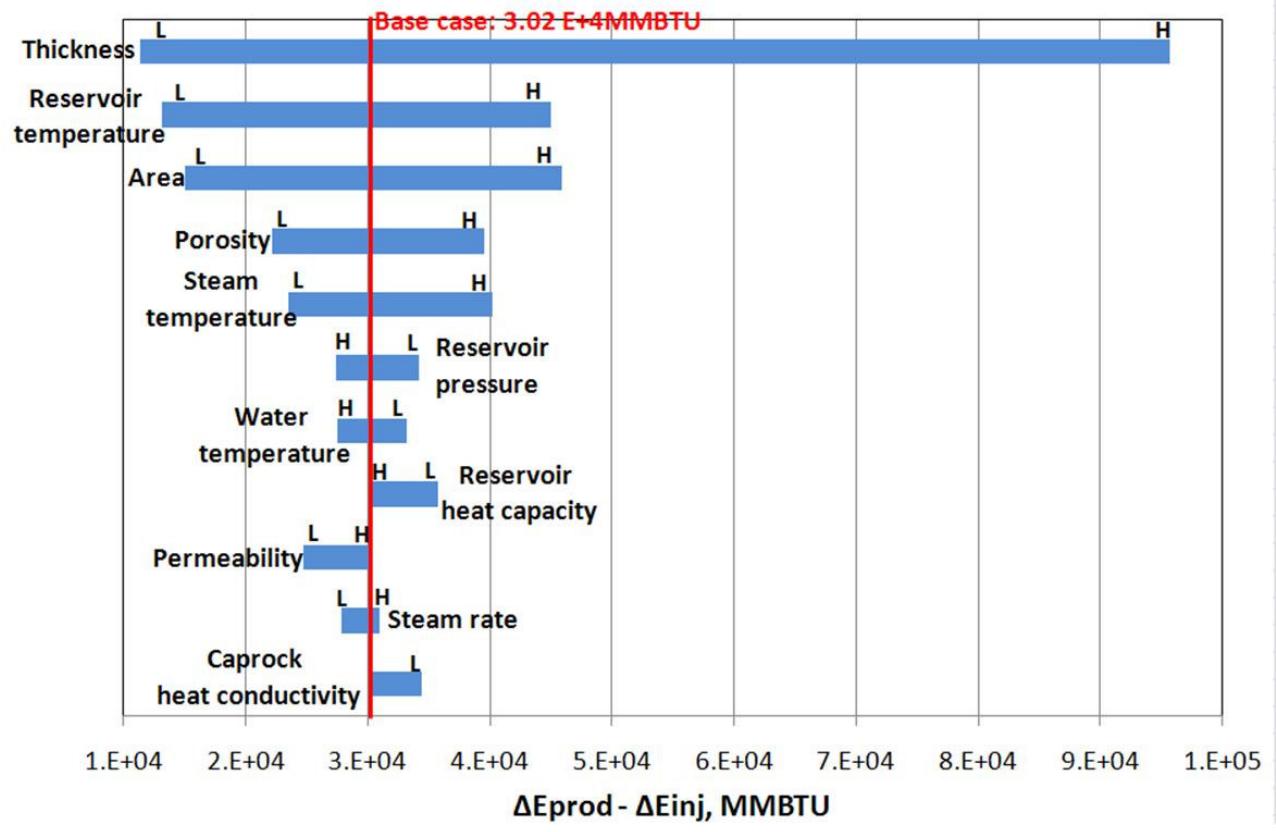

Fig. 12 Results of the sensitivity analysis.

\section{Geometry}

Greater reservoir thickness results in more net energy produced and vice versa smaller thickness leads to less energy recovery. The reason is that, when the thickness is greater, steam can be injected into the reservoir for longer before reaching the abandonment point (950 days compared to 7,100 days) and therefore more heat can be stored in the reservoir rock during the steam injection phase.

Similarly, a larger area results in more net energy produced. However, compared to the effect of reservoir thickness, an increase in area causes a smaller increase in net energy production, as a larger area also corresponds to a larger contact surface between reservoir formation and surrounding rock, resulting in a greater heat loss rate from the system. 


\section{Rock properties}

Variations in reservoir porosity and permeability may affect the abandoned time of the steamflooding process, which yields a difference in heat stored in the reservoir. A porosity change from $25 \%$ to $35 \%$ affects the net energy produced more than varied permeability change from 1,500 md to 5,000 md. High porosity denotes more pore volume in the reservoir, resulting in more heat being stored in the reservoir fluids, which can be released during the water injection phase. It must be stressed that, for a more rigorous sensitivity study, porosity and permeability should not be varied independently from one another, but rather according to a specific poro-perm relationship, representative of the rock type under investigation.

\section{Rock thermal properties}

The two key parameters involved in the heat transfer process investigated by this study are the thermal conductivity and the volumetric heat capacity. For the sensitivity analysis, the volumetric heat capacity of the reservoir is perturbed by $15 \%$. One low case of thermal conductivity of the cap rock is simulated, assuming that the surrounding rock has an extremely low thermal conductivity value, such as that of salt (Prats 1982). The results of this sensitivity show that a lower heat capacity results in more net energy produced, and vice versa. This is because a lower heat capacity requires a longer time to increase the reservoir temperature and so make the heavy oil mobile, which results in a longer heat storage period before steamflooding abandonment. Less-conductive cap rock results in more heat accumulated in the reservoir, which in turn causes more energy recovery through water injection.

\section{Initial reservoir conditions}

The initial reservoir temperature and pressure dictate the original amount of energy stored in the reservoir. They also determine for how long the reservoir can deliver prior to abandonment. The simulation results show that the reservoir temperature has a direct impact on the heat recovery, with higher temperatures resulting in a greater net energy 
rate. On the other hand, higher reservoir pressures result in lower net energy rates, due to earlier abandonment times, which diminish the amount of heat stored in the reservoir.

\section{Steam injection conditions}

Steam rate and steam temperature dictate how much energy is introduced in the reservoir during steamflooding. Higher temperature and rate result in more net energy produced during the water injection phase. However, it appears that temperature has a more pronounced effect.

\section{Water injection temperature}

The impact of injecting water at different temperature can help understand whether additional facilities (and associated costs) are required to heat the water prior to injection. The simulation results shows that low water temperature results in more net energy rate because of the higher energy extracted from the reservoir rock and also because of the smaller injection energy input.

\section{Summary of sensitivity variables}

The factors with the largest impact on the energy recovery during the water injection phase are the duration of the steam flood (which dictates the amount of heat accumulated in the reservoir) and the original reservoir energy in place. The parameters with the largest impact on the time for heat storage are the reservoir thickness, area, porosity, permeability, pressure and the steam injection rate. The parameters that strongly influence the original reservoir energy in place are reservoir temperature, heat capacity, thermal conductivity and steam temperature. Area, thickness and porosity also affect the energy in place as they represent how much fluid is stored in the reservoir. 


\section{CHAPTER IV}

\section{CALCULATION OF WELLBORE TEMPERATURE}

\section{Calculation of Heat Transfers in the Wellbore}

Heat transfers between fluid and surrounding formation as it moves through a wellbore is caused by difference between the fluid and formation temperature. For the production well, fluid heat losses raise the temperature of the surrounding formation. However, heat losses become more of a concern in injection wells rather than in production wells, especially in hot fluid injection where wellbore temperature is much greater than the formation temperature. If steam injectors are not insulated, heat from the steam transfers to some extent to the formation around wellbore, resulting in an increase in formation temperature. As a consequence, the steam is condensed before entering the reservoir.

For the injection well, our estimation of wellbore heat transfer referred to a semianalytical equation proposed by Ramey (1962). The Ramey model was developed based on a combination of a general energy balance and a mechanical energy balance, assuming well radius is small and acts as line-source well. Fluid temperature in any depth and time can be expressed as:

$$
T_{w}(D, t)=g_{G} D+T_{b}-g_{G} Z+\left[T_{i n j}(t)+g_{G} Z-T_{b}\right] e^{-D / Z}
$$

where the parameter $\mathrm{Z}$ is defined by:

$$
Z=\frac{w C_{p f}\left[\lambda+f(t) r_{t i} U\right]}{2 \pi \lambda r_{t i} U}
$$

and $f(t)$ is the transient heat conduction time function for earth shown in Fig. 13. For the time greater than one week, all solutions converge to a line source, in which the $f(t)$ can be expressed as: 


$$
f(t)=-\ln \frac{r_{c o}}{2 \sqrt{\alpha t}}-0.290
$$

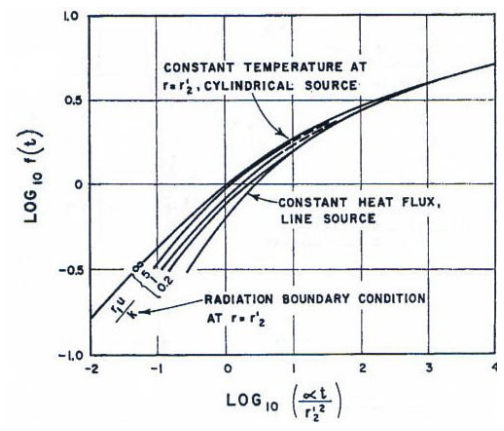

Fig. 13 Time function, $f(t)$, in the Ramey equation

During the heat recovery process, the injecting water is warmed up by the surrounding formation. The temperature of rock surrounding the wellbore is higher than the initial formation temperature because heat loss from the steam injection process is dissipated within the rock over a long time. In Ramey's equation, one important assumption is that the geothermal gradient is constant, in which the temperature reversal effect cannot be taken into account. Therefore, an approximation of new geothermal temperature at near wellbore region is investigated in the injection well.

For the production well, we generated temperature profile using a mechanistic model proposed by Hasan and Kabir (2002). The equation can be generalized in a case of steady-state flow, wellbore two-phase-flow.

$$
T_{w}=T_{e i b h}-g_{G} \sin \beta\left[(L-D)-\left(1-e^{(D-L) L_{R}}\right) / L_{R}\right]
$$

The relaxation length parameter, $\mathrm{L}_{\mathrm{R}}$ is defined as:

$$
L_{R}=\frac{2 \pi}{C_{f} w}\left[\frac{r_{t o} U_{t o} \lambda_{e}}{\lambda_{e}+\left(r_{t o} U_{t o} T_{D}\right)}\right]
$$


The dimensionless temperature, $\mathrm{T}_{\mathrm{D}}$, is estimated with validity for wells of small diameter and can be expressed at large time as:

$$
T_{D}=0.4063+\frac{1}{2} \ln t_{D}
$$

\section{Temperature Profile of the Injection Well}

\section{During steamflooding period}

Since steam injecting temperature is assigned at the bottomhole condition in the reservoir simulation run, we need to verify that the steam temperature at surface is in the possible range of operation. We use the Ramey method accounting for compressible fluid, which expressed as:

$$
\begin{aligned}
& T_{w}(D, t)=g_{G} D+T_{b}-\left(g_{G}+\frac{1}{778 c} Z+\left[T_{i}(t)+\left(g_{G}+\right.\right.\right. \\
& \left.\left.\frac{1}{778 C_{f}}\right) Z-T_{b}\right] e^{-D / Z}
\end{aligned}
$$

The geothermal gradient, $\mathrm{g}_{\mathrm{G}}$, expressed in above Eq. 30 is obtained using a linear interpolation between initial reservoir temperature of $125^{\circ} \mathrm{F}$ and surface temperature of $70^{\circ} \mathrm{F}$. Table 7 summarizes parameters used in calculation. We note the assumption of insulting material completed in the injection well to prevent reduce heat loss during the thermal process. 
Table 7 Parameters used in calculation of temperature profile of the injection well

\begin{tabular}{|c|c|}
\hline Parameter & Value \\
\hline Thermal conductivity of rock, BTU/ft/day $/{ }^{\circ} \mathrm{F}$ & 26.2 \\
\hline Specific heat capacity of rock, BTU $/ \mathrm{lb}_{\mathrm{m}} /{ }^{\circ} \mathrm{F}$ & 0.20 \\
\hline Thermal diffusivity of rock, $\mathrm{ft}^{2} /$ day & 0.95 \\
\hline Bulk density, $\mathrm{lb}_{\mathrm{m}} / \mathrm{ft}^{3}$ & 137 \\
\hline Inside tubing radius, $\mathrm{ft}$ & 0.102 \\
\hline Outside casing radius, $\mathrm{ft}$ & 0.276 \\
\hline Heat capacity of steam @ $450^{\circ} \mathrm{F}, \mathrm{BTU} / \mathrm{lb}_{\mathrm{m}} /{ }^{\circ} \mathrm{F}$ & 1.11 \\
\hline Geothermal gradient, ${ }^{\circ} \mathrm{F} / \mathrm{ft}$ & 0.04 \\
\hline Injection rate, bbl/day (Cold water equivalent) & 50 \\
\hline Fluid density, $1 b_{m} / \mathrm{ft}^{3}$ & 62.4 \\
\hline Overall heat transfer coefficient, BTU $/ \mathrm{hr} / \mathrm{ft}^{2} /{ }^{\circ} \mathrm{F}$ & 0.3 \\
\hline
\end{tabular}

Substituting fluid temperature back into Eq. 30 suggested that surface operating temperature during steamflood process is approximately $590^{\circ} \mathrm{F}$ as shown in Fig. 14. It is noted that the temperature profile is at 10 days of steam injection process. Steam injection over a long period affects heat accumulation around the injection well, thus higher bottomhole temperature. 


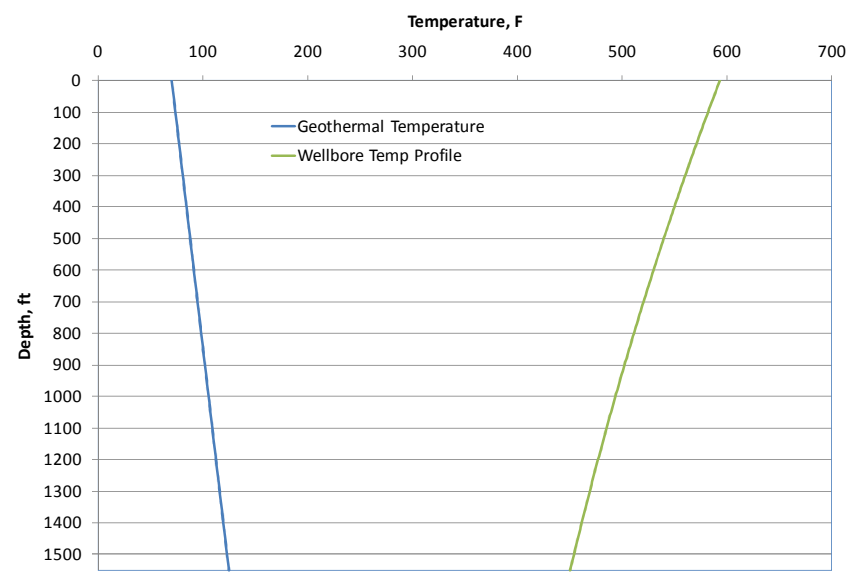

Fig. 14 Temperature profile of the injection well during steamflooding process. The surface temperature is $590{ }^{\circ} \mathrm{F}$ and the bottomhole temperature is $450{ }^{\circ} \mathrm{F}$.

\section{During water injection period}

We investigate the temperature reversal effect, in which the injecting water is warmed up by relatively hotter near-wellbore rock than the geothermal temperature. Heat losses that once dissipated to the vicinity of the injection well during steamflooding process increase the temperature of injecting water in the wellbore (Fig. 15). Therefore, change in geothermal gradient to some extent of the rock formation near the injection well resulting from steamflood process needs to be determined.

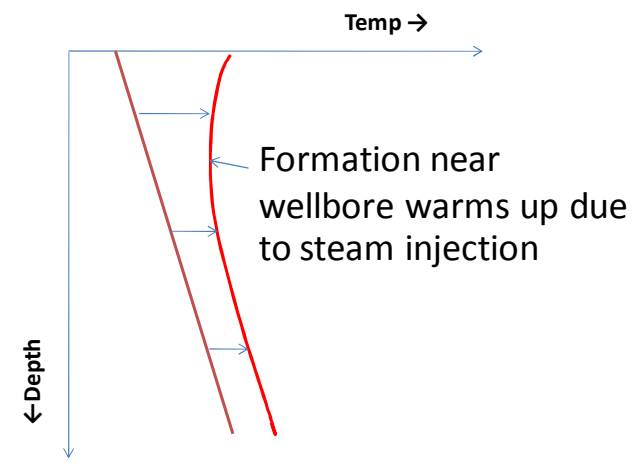

Fig. 15 Geothermal temperature near wellbore is raised as a result from heat dissipation to surrounding rock caused by steam injection 
Heat loss from wellbore is accumulated within surrounding rock during the steam flood process. The amount of heat transfers from wellbore fluid can be obtained by solving Eq. 31 and Eq. 32. The amount of heat that stored within surrounding rock can be expressed in Eq. 33.

$$
\begin{aligned}
\dot{Q} & =2 \pi r_{1} U\left(T-T_{e}\right) \\
Q & =\int_{0}^{\tau} \dot{Q} d t \\
Q & =M_{\text {rock }} C_{p, \text { rock }} \Delta T
\end{aligned}
$$

The rock mass that is heated by the steam can be expressed as:

$$
M_{\text {rock }}=\pi \rho \Delta Z\left(\delta^{2}-r_{c o}^{2}\right)
$$

The moving thermal penetration thickness, $\delta$, defines how far that heat can disperse into the surrounding rock in radial direction as a function of time and thermal diffusivity. Heat penetrated within the rock, $\delta$, as shown in Fig. 16 is expressed as:

$$
\delta(t)=\sqrt{\alpha t}
$$

where $\quad \delta \quad=$ Moving thermal penetration thickness
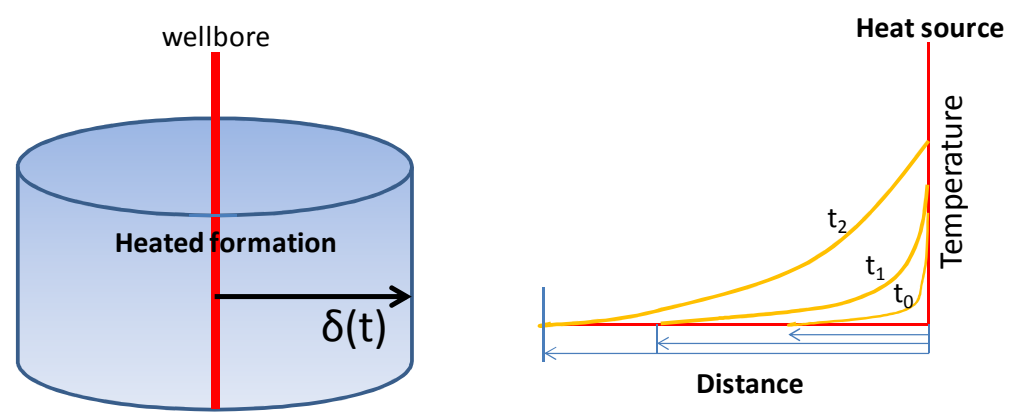

Fig. 16 Volume of rock is heated depending on distance that heat could penetrate defined by moving thermal penetration thickness 
Therefore, the new geothermal temperature can be obtained by solving for $\Delta \mathrm{T}$ in Eq. 33 and is expressed as:

$$
T_{G}^{*}=T_{G}+\Delta T
$$

Fig. 17 illustrates the bottomhole fluid temperature during water injection phase is $89^{\circ} \mathrm{F}$ $\left(32^{\circ} \mathrm{C}\right)$ when injecting water with $86^{\circ} \mathrm{F}\left(30^{\circ} \mathrm{C}\right)$ of surface temperature, using the adjusted geothermal temperature. Incremental of $3 \%$ received from the formation near the wellbore before entering the reservoir is considered to be negligible in our study. However, more detail studies in impact of temperature rises in the formation from steamflooding to increase water temperature is recommended.

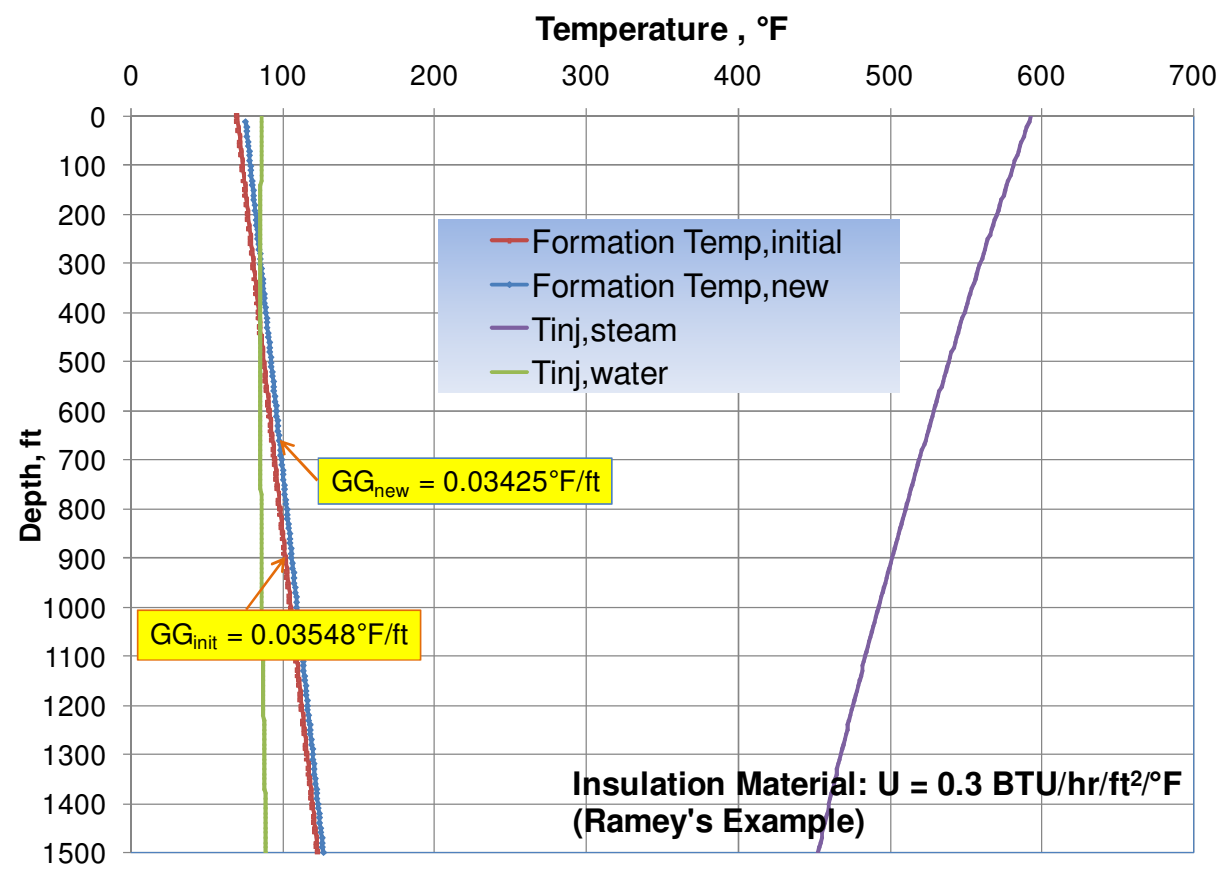

Fig. 17 Geothermal temperature around the well and the temperature profile of water injection influenced by new geothermal energy 


\section{Temperature Profile of the Production Well}

Since the investigation of fluid temperature of the injector caused by temperature reversal effect suggested that impact of raise in water temperature can be negligible, the reservoir simulation result in chapter III can be readily used to generate the temperature profile in the wellbore. The bottomhole temperature data over entire heat recovery phase (3,800day) from the base case simulation run were discretized into every 10 days interval. Fluid temperature in the wellbore is obtained by applying the Hasan and Kabir correlation. Note that we assume water properties in the calculation. The heat transfer coefficient, U, expressed in Eq.28 can be estimated as:

$$
\frac{1}{U}=\frac{1}{h_{1}}+\frac{r_{t i} \ln \left(\frac{r_{t o}}{r_{t i}}\right)}{\lambda_{t}}+\frac{r_{t i}}{h_{2} r_{t o}}+\frac{r_{t i}}{h_{2} r_{c i}}+\frac{r_{t i} \ln \left(\frac{r_{c o}}{r_{c i}}\right)}{\lambda_{c}}
$$

Table 8 summarizes data used for calculation of fluid temperature of the production well. We assumed conventional well completion in the producer, causing greater heat loss than that in the injection well.

Table 8 Parameters used in calculation of temperature profile of the production well

\begin{tabular}{lr}
\hline \multicolumn{1}{c}{ Parameter } & \multicolumn{1}{c}{ Value } \\
\hline Water rate, Bbl/day & 250 \\
Tubing inside radius, in & 1.2005 \\
Tubing outside radius, in & 1.4375 \\
Casing inside radius, in & 3.0245 \\
Casing outside radius, in & 3.3125 \\
Thermal conductivity of tubing, BTU/ft/day $/{ }^{\circ} \mathrm{F}$ & 600.0 \\
Thermal conductivity of cement, BTU/ft/day $/{ }^{\circ} \mathrm{F}$ & 96.5 \\
Thermal conductivity of formation, & \\
BTU/ft/day $/{ }^{\circ} \mathrm{F}$ & 26.2 \\
Thermal conductivity of water, BTU/ft/day $/{ }^{\circ} \mathrm{F}$ & 8.1 \\
Surface temperature, ${ }^{\circ} \mathrm{F}$ & 70.0
\end{tabular}


Using Eq. 37, the average wellhead temperature at the production well over 3,800 day of production is approximately $161^{\circ} \mathrm{F}\left(72^{\circ} \mathrm{C}\right)$ as shown in Fig. 18 using Trapezoidal rule. Since the average bottomhole temperature of the producing fluid is $185^{\circ} \mathrm{F}$, heat loss during from the producing well is approximately $13 \%$ of the total heat recovery from the reservoir.

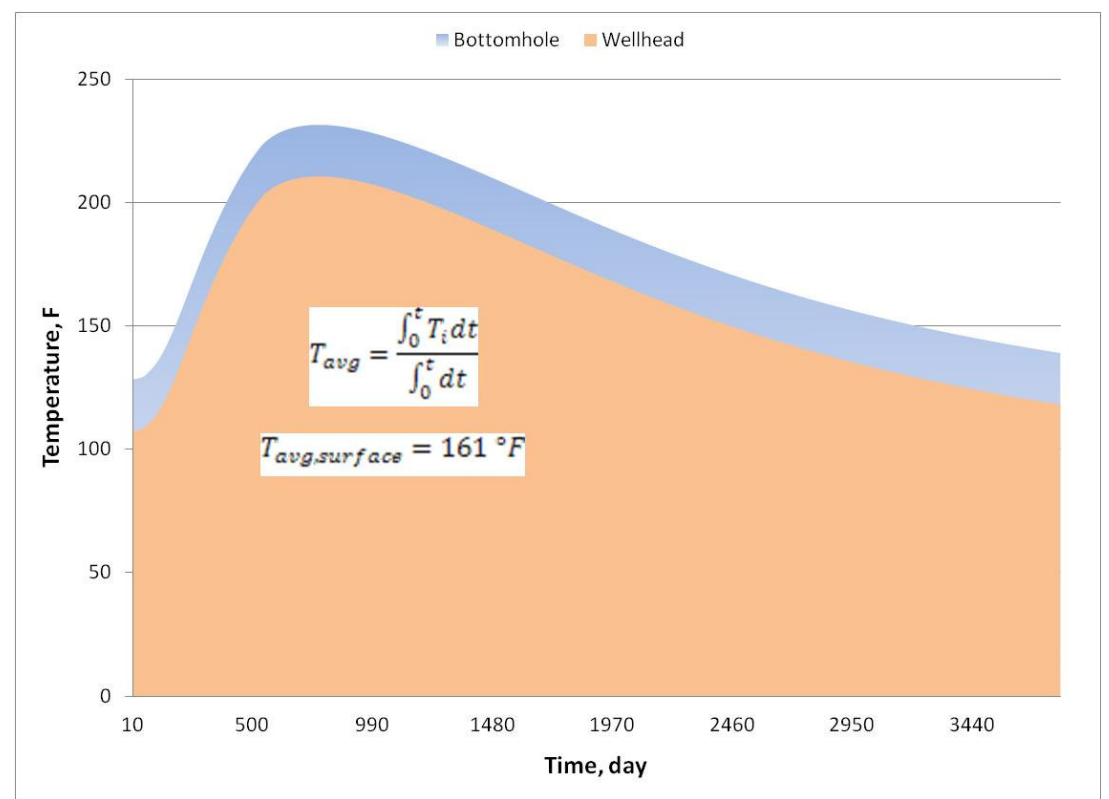

Fig. 18 Temperature profile of the production well during heat recovery phase. The average wellhead temperature of producing fluid is obtained by integrating surface temperature profile divide by total production time. 


\section{CHAPTER V}

\section{SURFACE OPERATIONS AND ECONOMIC CONSIDERATION}

\section{Application of Geothermal Energy}

To classify the geothermal resources, the enthalpy of the geothermal fluids that can be considered more or less proportional to temperature is used to expressed heat content of the fluids and can gives an idea of their values (Geothermal Energy: Utilization and Technology 2006). Based on temperature ranges, the artificial geothermal reservoir is classified in a group of low enthalpy resources, in which its average temperature is below $90^{\circ} \mathrm{C}\left(194^{\circ} \mathrm{F}\right)$. Utilization of the low enthalpy resource for both electric power generations as well as direct uses may be limited; however, in view of the rapidly rising energy demands and costs of energy in modern society, it becomes even more important. Based on Lindal diagram (Fig. 19), which show the possible uses of geothermal fluids at different temperatures, hot producing fluid of $72^{\circ} \mathrm{C}\left(161^{\circ} \mathrm{F}\right)$ from the artificial geothermal energy is more compatible for direct use applications. 


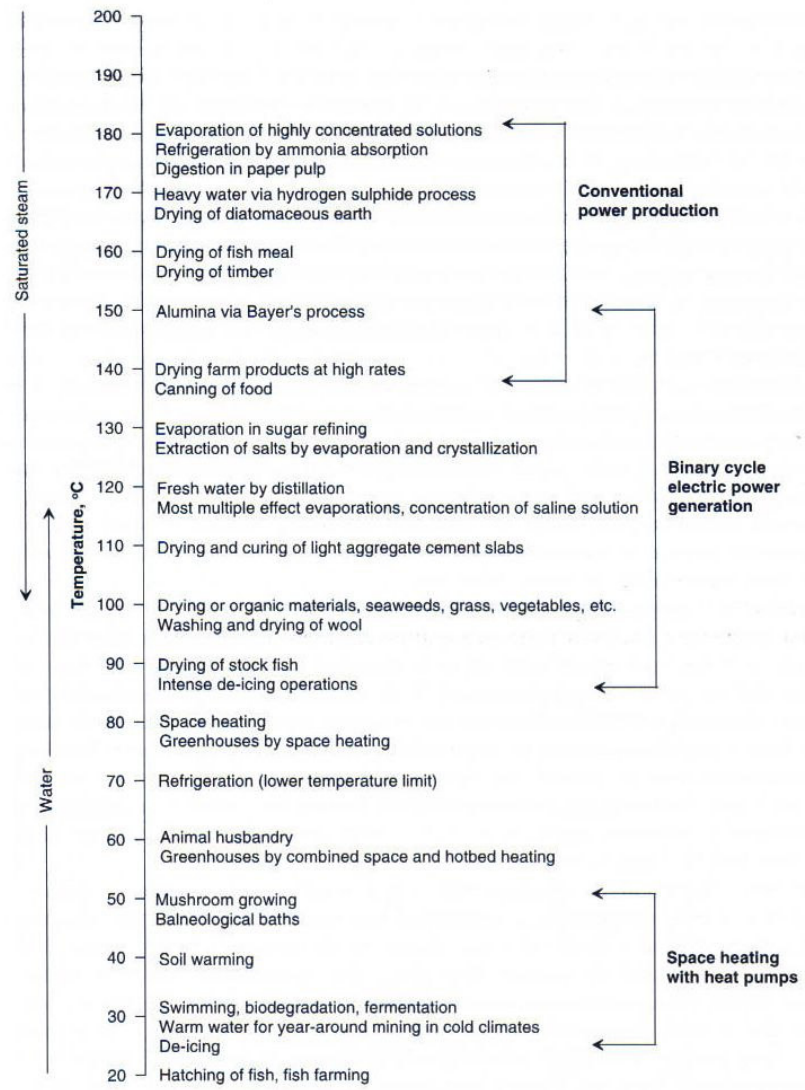

Fig. 19 Lindal diagram illustrate general temperature requirements of a spectrum of direct-use applications of geothermal energy but also ranges for electric power generation.

Heavy oil fields are commonly located faraway from agricultural and aqua-cultural areas where direct uses are applicable for low enthalpy resources. In such cases, transportation of thermal fluid in pipeline in long distances can cause substantial temperature drop inevitably. An approximation of heat losses in surface lines is beyond our scope of the study; however, a general idea of heat loss in the pipeline is given. With the flow rate varying between 5 and $15 \mathrm{lps}$ in a pipe of diameter $0.15 \mathrm{~m}$, temperature drops in the range $0.1-1.0{ }^{\circ} \mathrm{Ckm}^{-1}$ in insulated pipelines and $2-5{ }^{\circ} \mathrm{Ckm}^{-1}$ in uninsulated pipelines are common (Gupta and Roy 2007). Besides, Temperature losses are lower for larger diameter pipes or higher flow rates. 
One possibility for direct use application, which is suitable for heat recovery from the artificial geothermal resources, is geothermal heat pumps. A heat pump makes use of the relative stable temperature at a depth of a few meters in the ground. During winter, the subsurface temperature is warmer than the room temperature inside a house, while during summer, the subsurface temperature may be cooler. The heat pump can be, therefore, used both for heating as well as cooling. Uses of heat pump application require temperature of the fluid in the range of $30^{\circ} \mathrm{C}$ to $50^{\circ} \mathrm{C}$.

For electricity generation, heat recovery from the low enthalpy resources is less desirable. Base on the Lindal diagram, the minimum requirement of fluid temperature to be able to generate electrical power using the binary cycle is more than the arrival fluid temperature obtained from our synthetic field. However, recent developing technology of waste heat recovery for electricity generation is called "Ener-G-Rotors" (Kho 2008). The Ener-G-Rotors use inlet temperature fluid between $65^{\circ} \mathrm{C}$ and $150^{\circ} \mathrm{C}$. This technology is based on Rankine cycle, in which heated fluid through a tube heats pressurized fluid in a second tube via a heat exchanger. The second tube is a closed loop; the so-called working fluid flowing through it vaporizes and travels into a larger space called an expander. The expanding vapor in Ener-G-Rotors' system turns the "gerotor", which is two concentric rotors. The inner rotor attaches to an axle, and the outer rotor is a kind of collar around it. The rotors have mismatched gear teeth, and when vapor passing between them forces them apart, the gears mesh, turning the rotor. The current technology of the Ener-G-Rotors works well in lower temperature range than that in the typical organic Rankine cycle (Binary system). It also designs for electricity generation in a small scale, which is less than 200kW (Ener-G-Rotors 2009). The efficiency in converting heat into electricity of the Ener-G-Rotors is $10 \%$ to $15 \%$ (Kho 2008). The technology is, however, not well-established for the time being since there is no publication about this application tested in the industry. It is expected that this technology will be more proven in the near future to vastly extend utilization in lowenthalpy resources. 


\section{Surface Facilities for Heat Recovery Scheme}

To justify economic feasibility, we use electricity generation as a mean to generate revenue for this project. We choose the Ener-G-Rotors technology to incorporate in the heat recovery scheme assuming this technology can generate electrical power as provided in literature. The heat recovery scheme for electricity generation is slightly modified and is shown in Fig. 20. As soon as hot producing liquid is recovered at the wellhead, we will instantly make use of heat energy carried by medium to avoid temperature loss from the system. The fluid is transmitted to the Ener-G-Rotors system for electricity generation and then is transported to the separator to extract residual oil. Outlet water from the separator could be processed into the water treatment unit depending on necessity. The water is then combined with water from fresh sources before injecting into the reservoir again. It is noted that concerns should be made in qualities of the fluid before entering into heat transmission equipment. Less purities fluid could cause some mechanical problems, which need to be investigated during surface facility design phase.

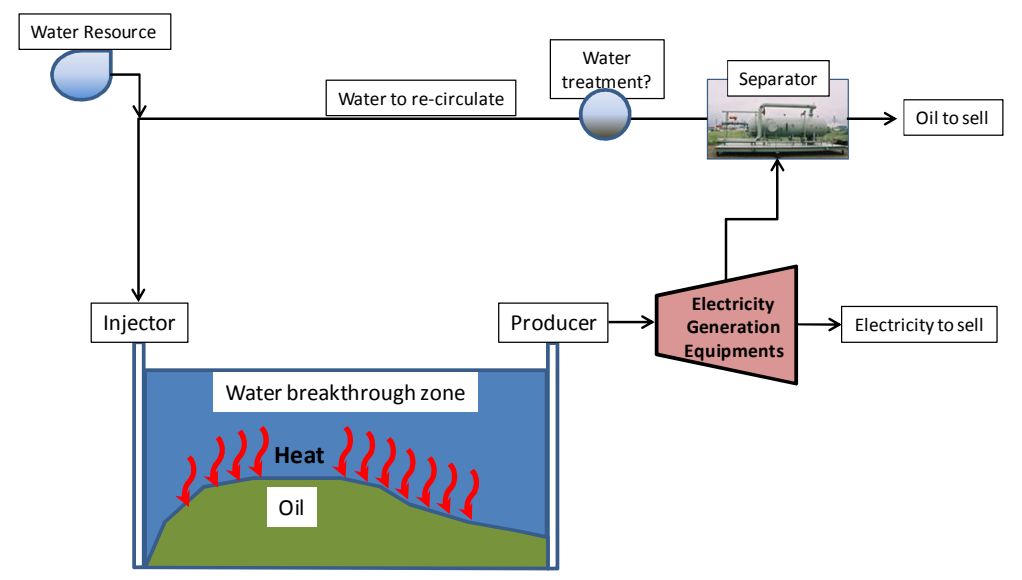

Fig. 20 Heat recovery scheme for electrical power generation 


\section{Estimation of Electricity Generated From Heat}

The amount of electricity can be determined in the case that revenue of the project is generated by electricity generation. The Ener-G-Rotors, for which the efficiency is about $10-15 \%$, is more suitable than the conventional Binary cycle because of operating temperature ranges. Typical energy conversion from heat into electricity can be expressed as:

$$
\text { Electrical power }=w C_{f}\left(T-T_{r}\right) \eta
$$

Table 9 show parameters used in electricity calculation. It is noted that the flow rate is based on reservoir simulation result. The result shows that, for electricity generating per one pattern is approximately $14 \mathrm{~kW}$.

Table 9 Parameters used for calculating of electricity generation

\begin{tabular}{lr}
\hline \multicolumn{1}{c}{ Parameter } & Value \\
\hline Flow rate, bbl/day & 250 \\
Fluid density, $\mathrm{lb} / \mathrm{ft}^{3}$ & 62.4 \\
Specific fluid heat capacity, & \\
$\mathrm{BTU} / \mathrm{lb} /{ }^{\circ} \mathrm{F}$ & 1.04 \\
Fluid temperature, ${ }^{\circ} \mathrm{F}$ & 161 \\
Reference temperature, ${ }^{\circ} \mathrm{F}$ & 70 \\
Efficiency of the thermal conversion, & \\
$\%$ & 15 \\
\hline
\end{tabular}




\section{Case Example: Chena Hot Springs Field, Alaska}

Chena Hot Springs is a good example of the recent geothermal power plant from low enthalpy resources to operate (Chena Power 2007). The electricity power generated from this field is used to running its own community and resort with capacity $200 \mathrm{~kW}$ per unit. The modified Organic Rankine Cycle (ORC), called the Pure Cycle, is designed to use inlet hot fluid with such low temperature as $73^{\circ} \mathrm{C}\left(164^{\circ} \mathrm{F}\right)$ by replacing with different working fluid from conventional ORC. This ORC require 29,600 bbl/day of inlet fluid to generate $200 \mathrm{~kW}$ of power and consume $40 \mathrm{~kW}$ loads.

\section{Economic Consideration}

In consideration of the economics of the project, the minimum criteria for running the project are at the point where the electrical power is at least more than power consumption for operating all equipments in the heat recovery scheme. From Fig. 20, the system requires one surface injection pump, one fluid lifting pump at the production well, and the electricity-generating system (Ener-G-Rotors 2009). For the water injecting pump, the power required for injecting $500 \mathrm{bbl} / \mathrm{d}$ of water with $50 \%$ in efficiency is approximately $7.2 \mathrm{~kW}$ using a conventional formula for power requirement of pumps. For an artificial lift in the production well, we selected a sucker rod pump because its diameter is fit with wellbore size of the producer without additional recompletion of the well. The power requirement for running this pump can be estimated using the following equation (Takacs N/A).

$$
H P=1.7 \times 10^{-5} Q \Delta P
$$

where $\quad \mathrm{Q}=$ Pumping rate $(\mathrm{bbl} / \mathrm{d})$

$$
\Delta \mathrm{P} \quad=\text { Lifting power }(\mathrm{psi})
$$

In our investigation, we assumed that the pump is to lift $250 \mathrm{bbl} / \mathrm{d}$ of water from the borehole at 1,500 $\mathrm{ft}$ to surface. Therefore, the power requirement for the lifting pump is approximately $2 \mathrm{~kW}(2.76 \mathrm{HP})$. In addition, power consumption for the electricity generation unit for the binary cycle system is typically $10 \%-15 \%$ of the gross generation 
(Geothermal Energy: Utilization and Technology 2006). If we assume that the Ener-GRotors system consumes the same amount of power in operating the unit, the power requirement for this unit is estimated about $2 \mathrm{~kW}$ ( $15 \%$ of the gross generation). Hence, the total power consumption for the heat recovery scheme is approximately $11.2 \mathrm{~kW}$. Therefore, net electrical power generated by the Ener-G-Rotors is around $3 \mathrm{~kW}$ over 3,800 days of production. The cumulative energy generation is $246,240 \mathrm{kWh}$ accounting for $90 \%$ downtime.

It is note that for Ener-G-Rotors technology, we do not analyze cash flow of the project because this state-of-art technology has not obviously been commercialized within in any industry. Moreover, we need to include analyze of heat loss in surface lines which requires more realistic data of production wells and their locations in order to be precisely examine net income. For current stage of the study, we assume that multiplication of 100 wells should be used in calculating total power generation of one heavy oil field.

The example of Chena Hot Springs field is used to depict the possibility of generating electricity from such low geothermal resources similarly to our case. The design of the Pure Cycle ORC is compatible with our artificial geothermal reservoir in an aspect of inlet temperature but not for volumetric flow rate. Large flow rate cannot be delivered under the specific synthetic field that is chosen for the study. However, it is very likely to that higher flow rate can be from other field examples. 


\section{CHAPTER VI}

\section{CONCLUSIONS AND RECOMMENDATIONS}

\section{Conclusions}

This study presents the investigation of the heat balance in the artificial geothermal reservoir. The study also examines the heat transfer in the wellbore and the current technology of heat-electricity transmission for the surface facilities. The artificial geothermal potential of the heavy oil reservoir, which once was undergone steamflooding during the thermal process, could be harnessed by water injection. The amount of harvested heat could be used either for direct application or electricity generation depending on the arrival fluid temperature at surface.

Heat transfer within the system can be illustrated by fluid temperature in each node as shown in Fig. 21. In this synthetic field, we inject water with $30^{\circ} \mathrm{C}$ in temperature into the insulated injector. The result of heat balance study shows that the water temperature is increased as flow downwards the well very slightly. The water flowed into the reservoir is warmed by the formation rock and the heat transverse from overburden and underburden rock, resulting in increasing in fluid temperature to be $85^{\circ} \mathrm{C}$. The water is then flowed along the well, exchanging its energy to surrounding. Heat loss in the wellbore is around $13 \%$ causing the fluid temperature at surface to be $72^{\circ} \mathrm{C}$ before

entering the electricity-generation unit. Electrical power generated by Ener-G-Rotors system is approximately $14 \mathrm{~kW}$ with this arrival fluid temperature, thus the net electrical power generation of $3 \mathrm{~kW}$ per one pattern over 3,800 days of production. 


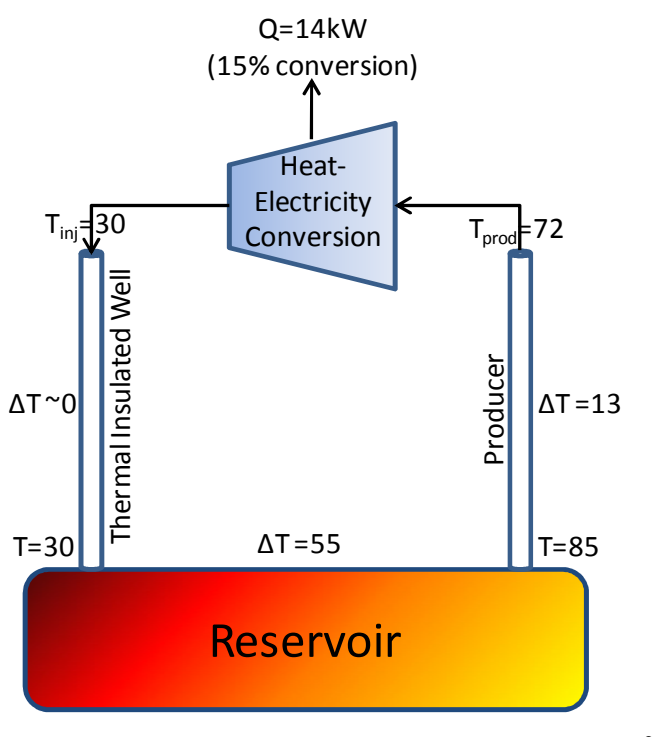

Fig. 21 Energy flow diagram describing fluid temperature and the electricity conversion in the system

The sensitivity study of the reservoir/injection parameters identifies important parameters that would affect potential harnessing of geothermal energy. The amount of heat stored in the reservoir, which is subsequently recovered, depends on not only the heat flux injected during steamflooding as functions of steam temperature, injection rate and duration of the steamflooding, but also on the thermal properties of reservoir fluids, reservoir rock, overburden and underburden. These have an impact on the overall heat transfer process, including heat accumulation and dissipation. Results of the sensitivity study show that impacts on energy harvesting can be characterized as two factors: the duration of steam flood and the original energy in-place. The parameters with the largest impact on the time for heat storage are the reservoir thickness, area, porosity, permeability, pressure and the steam injection rate. The parameters that strongly influence the original reservoir energy in place are reservoir temperature, heat capacity, thermal conductivity and steam temperature.

The result from energy comparison confirms that we can harness geothermal potential from the artificial geothermal heavy oil reservoir. Using state-of-art technology, it is 
obviously shown that net electrical power can generate revenue for the project. Additionally, direct use application could be adapted to generate extra revenue. However, detail cash flow analyzes need to including tax credit and revenue from selling oil.

\section{Recommendations}

We recommend improving the investigation of artificial geothermal potential in the following area.

1. Include the analysis of ultra-heavy oil fields, in which the heat capacity of the oil is greater, resulting in higher stored geothermal potential.

2. Dynamically couple compositional reservoir simulations with computational codes for the modeling of heat exchange between wellbore and surrounding formation, and between reservoir and over-/under-burden. There are limitations in the current commercial packages that prevent this type of integrated analysis.

3. Perform detailed studies on state-of-art technology to convert heat from lowenthalpy resources ("waste energy") into electricity.

4. Incorporate the heat recovery process (from reservoir to delivery point) in cash flow analyses to assess the overall commercial feasibility of this novel concept. This would include potential "tax credits" to promote clean energy generation (as it is already the case for conventional geothermal exploitation), which could permit greater investments during the oil-production phase of the overall project. 


\section{REFERENCES}

Aziz, K., Ramesh, A.B., and Woo, P.T. 1987. Fourth SPE Comparative Solution Project: Comparison of Steam Injection Simulators. SPE Journal of Petroleum Technology 39 (12): 1576-1584. doi: 10.2118/13510-PA.

Castrup, S.G. 2001. Recommended Practices for Slim-Hole Steam Injectors. Paper SPE 68808-MS presented at the SPE Western Regional Meeting, Bakersfield, California, 26-30 March.

Chase, C.A. and O'Dell, P.M. 1973. Application of Variational Principles to Cap and Base Rock Heat Losses. SPE Journal 13 (4): 200-210. doi: 10.2118/4139-PA.

Chena Power. 2007. 400kW Geothermal Power Plant at Chena Hot Springs, Alaska. Final report for Alaska Energy Authority, Chena Power LLC. USA.

Curtis, C., Decoster, E., Garcia, A.G. et al. 2002. Heavy-Oil Reservoirs. www.slb.com/media/services/resources/oilfieldreview/ ors02/aut02/p30_51.pdf. Downloaded 7 July 2009.

Ener-G-Rotors. 2009. Convert Your Low Temperature Waste Heat to Electricity. http://www.ener-g-rotors.com/. Downloaded 1 December 2009.

Geothermal Energy: Utilization and Technology. 2006. Ed Dickson, M.H. and Fanelli, M. Paris: CNR Institute of Geosciences and Earth Resources.

Goda, H.M. and Behrenbruch, P. 2004. Using a Modified Brooks-Corey Model to Study Oil-Water Relative Permeability for Diverse Pore Structures. Paper SPE 88538MS presented at the SPE Asia Pacific Oil and Gas Conference and Exhibition, Perth, Australia, 18 - 20 October.

Gupta, H. and Roy, S. 2007. Geothermal Energy: An Alternative Resource for the 21st Century. Original edition. St. Louis, Missouri : Elsevier Science.

Hasan, R. and Kabir, S. 2002. Fluid Flow and Heat Transfer in Wellbores. Original edition. Society of Petroleum Engineer.

Hinkle, A. 2006. Heavy Oils: A Worldwide Opportunity. www.slb.com/media/services/resources/articles/heavyoil/200801_ao_heavy_oil_ recovery.pdf. Downloaded 10 September 2009.

Kho, T. 2008. Electricity from Waste Heat. www.technologyreview.com/business/210701/?a=f. Downloaded 1 March 2010. 
Messner, G.L. 1990. A Comparison of Mass Rate and Steam Quality Reductions to Optimise Steamflood Performance. Paper SPE 20761-MS presented at the SPE Annual Technical Conference and Exhibition. New Orleans, Louisiana, 23-26 September.

Miller, G. 2008. A Heavy Prospect. World Pipelines (March 2008).

Prats, M. 1982. Thermal Recovery. Original edition. SPE Monograph. Richardson TX: Society of Petroleum Engineer.

Ramey JR. 1962. Wellbore Heat Transmission. SPE Journal of Petroleum Technology 14 (4): 427-435. doi: 10.2118/96-PA.

Takacs, G. Power Efficiency of Sucker-Rod Pumping. http://www.ogbus.com/eng/authors/Takacs/Takacs_1.pdf. Downloaded 1 May 2010.

Teodoriu, C., Falcone, G., and Espinel, A. 2007. Letting Off Steam and Getting into Hot Water - Harnessing the Geothermal Energy Potential of Heavy Oil Reservoirs. Paper presented at the 20th World Energy Congress, Rome, Italy.

Valbuena, E., Bashbush, J.L., and Rincon, A.C. 2009. Energy Balance in Steam Injection Projects Integrating Surface-Reservoir Systems. Paper SPE 121489-MS presented at the Latin American and Caribbean Petroleum Engineering Conference, Cartagena de Indias, Colombia, 31 May-3 June.

Vinsome, P.K.W. and Westerveld, J. 1980. A Simple Method for Predicting Cap and Base Rock Heat Losses in' Thermal Reservoir Simulators. Journal of Canadian Petroleum Technology 19 (3). doi: 10.2118/80-03-04.

Weatherford. 2006. http://www.weatherford.com/weatherford/groups/public/ documents/general/wft019346.pdf. Downloaded 1 November 2009.

Weinstein, H.G. 1972. A Semi-Analytic Method for Thermal Coupling of Reservoir and Overburden. SPE Journal 12 (5): 439-447. doi: 10.2118/3597-PA.

Zhang, L., Yuan, J. 2008. Energy from Abandoned Oil and Gas Reservoirs. Paper SPE 115055-MS presented at the 2008 SPE Asia Pacific Oil \& Gas Conference and Exhibition, Perth, Australia, 20-22 October.

Ziegler, V.M. 1987. A Comparison of Steamflood Strategies: Five-Spot Pattern vs. Inverted Nine-Spot Pattern. SPE Reservoir Engineering 2 (4): 549-558. doi: 10.2118/13620-PA. 


\section{APPENDIX}

THE ECLIPSE DATA FILE FOR THE BASE CASE SCENARIO

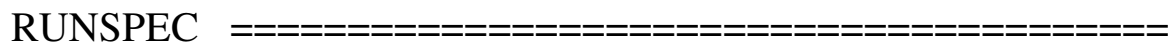

START

1 'JAN' 2000 /

FIELD

DIMENS

$151510 /$

WATER

OIL

GAS

COMPS

31

FULLIMP

THERMAL

HWELLS

-- Specifies maximum number of well and groups of wells

WELLDIMS

$9 \quad 50 \quad 9 \quad 5 /$

NINEPOINT

-- Ninepoint Transmissibility option, adds diagonal transmissibility values to the grid as non-neighbor connections in the XY plane

ROCKDIMS

-- Rock over and underburden dimensions

$11 * 20 /$

-- Use single segment MSW to get 'better' answer

--OPTIONS3 
$--61 * 1 /$

--FMTOUT

GRID

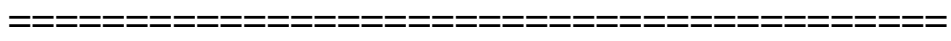

INIT

TOPS

$225 * 1500 /$

DXV

$3 * 8.6312 * 17.25$ /

DYV

$12 * 17.253 * 8.63$ /

DZV

$10 * 10 /$

ACTNUM

$2250 * 1 /$

PERMX

$2250 * 1500 /$

PERMY

$2250 * 1500 /$

PERMZ

$2250 * 1500 /$

PORO

$2250 * 0.3 /$

MULTIPLY

'PERMX' $0.5131315110 /$

'PERMX' 0.541513151 10/

'PERMY' $0.513 \quad 1 \quad 15110 /$

'PERMY' 0.541513151 10/

'PORO' $0.513 \quad 112110 /$

'PORO' $0.25131315110 /$ 
'PORO' $0.54151315110 /$

'PERMZ' $1115115110 /$

I

THCONR

-- Thermal conductivity of rock and fluids btu/ft/day $/{ }^{\circ} \mathrm{F}$

$2250 * 23.4 /$

HEATCR

--rock volumetric heat capacity value for each cell $\mathrm{Btu} / \mathrm{ft} 3 /{ }^{\circ} \mathrm{F}$.

$2250 * 42.3 /$

ROCKPROP

-- Property data for the base or cap rock

-- rock n, init temp, rock conductivity, vol heat capacity,

$11252435 /$

I

ROCKCON

-- Connection data for cap and base rocks

-- cap rock

$\begin{array}{lllllllll}1 & 1 & 15 & 1 & 15 & 1 & 1 & \text { 'K-' } 1.0 /\end{array}$

-- base rock

11151151010 'K+' 1.0 /

l

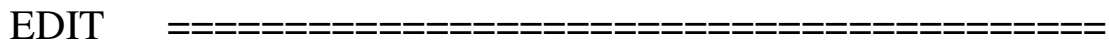

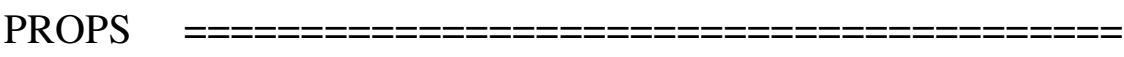

CNAMES

C1 C2 HEAVY /

KVCR

-- C1 C2 HEAVY

1.23E6 $212 \quad 1^{*}$

833.4E6 155.4E3 1* 


$\begin{array}{lll}0 & 0 & 1^{*} \\ 16000 & 4000 & 1 \\ 0 & 480 & 1^{*} \\ --0 & 460 & 1^{*} \\ \text { / } & & \end{array}$

TCRIT

$1259.671409 .6710000 /$

PCRIT

225. 140. $100.0 /$

MW

250450600 /

CREF

.00005.00005.00005 /

DREF

52.357 .6461 .2 /

THERMEX1

.00036.00037.00038 /

ZFACTOR

0.960 .970 .99 /

THANALB

SPECHA

$.53 .550 .6 /$

HEATVAP

$230.0100 .0 /$

TEMPVD

--Depth Temperature

1500.0125 .0

$1600.0125 .0 /$

STCOND 
--Temp Pressure

$60 \quad 14.7 /$

SWFN

-- SWAT KRW PCW

$\begin{array}{lll}4500 & .0000 & 0.0\end{array}$

$\begin{array}{lll}4900 & 0003 & 0.0\end{array}$

$\begin{array}{lll}.5300 & .0018 & 0.0\end{array}$

$\begin{array}{llll}.5700 & .0049 & 0.0\end{array}$

$\begin{array}{lll}.6100 & .0101 & 0.0\end{array}$

$\begin{array}{lll}.6500 & 0177 \quad 0.0\end{array}$

$\begin{array}{lll}.6900 & 0279 & 0.0\end{array}$

$\begin{array}{lll}.7300 & 0410 & 0.0\end{array}$

$\begin{array}{lll}.7700 & .0572 & 0.0\end{array}$

$\begin{array}{lll}.8100 & .0768 & 0.0\end{array}$

$\begin{array}{lll}.8500 & .1000 \quad 0.0\end{array}$

$\begin{array}{lll}1.0000 & .1000 & 0.0\end{array}$

/

SGFN

-- SGAS KRG PCG

$.0000 \quad 0000 \quad 0.0$

$\begin{array}{lll}.0600 & .0000 & 0.0\end{array}$

$\begin{array}{lll}.1090 & 0063 & 0.0\end{array}$

$\begin{array}{lll}.1580 & 0179 & 0.0\end{array}$

$\begin{array}{lll}2070 & .0329 & 0.0\end{array}$

$\begin{array}{lll}.2560 & 0506 & 0.0\end{array}$

$\begin{array}{lll}.3050 & 0707 & 0.0\end{array}$

$\begin{array}{lll}.3540 & .0930 & 0.0\end{array}$

$\begin{array}{lll}4030 & .1171 & 0.0\end{array}$

$\begin{array}{lll}.4520 & .1431 & 0.0\end{array}$ 


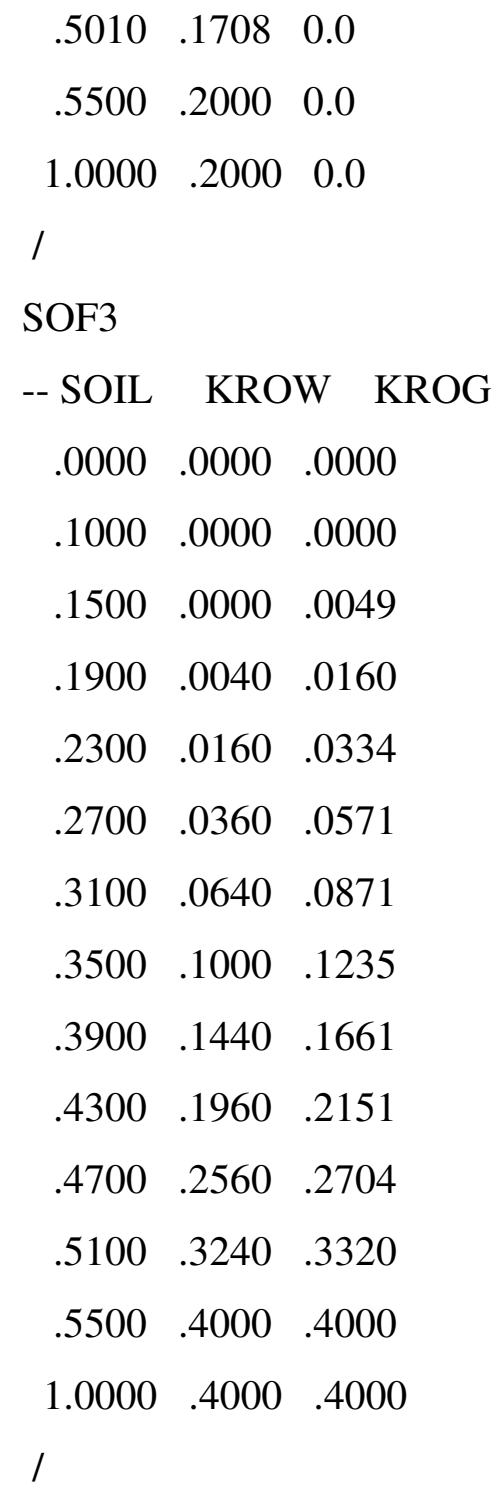




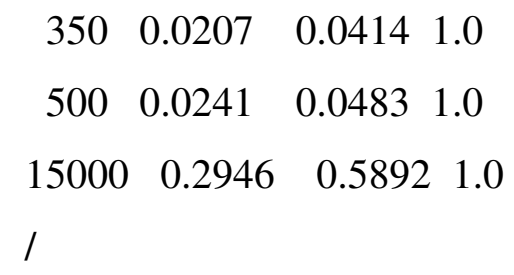

-- Ddat Pdat Dwoc Pcog Dgoc Pgoc It1 It2 Iac Iin----------------------------- 


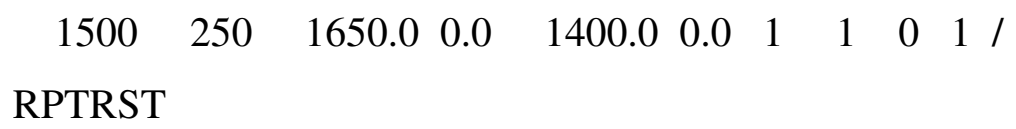

--OUTPUT FOR THE PRINT FILE

PRES TEMP ENERGY TW SPENWAT SOIL SWAT SGAS VOIL YMF XMF TEMP HOIL HWAT/

RPTSOL

PRES TEMP ENERGY TW SPENWAT SOIL SWAT SGAS VOIL YMF XMF TEMP HOIL HWAT/

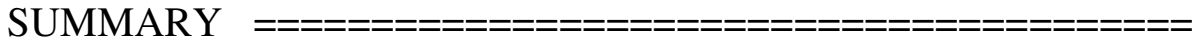

EXCEL

FPR

FOPT

FWPT

FWCT

FWIR

FWIT

FLPR

FOIP

FERCK

FEOIL

FEWAT

FETOT

FEWPC

FEIR

FEIT

FEPR

FEPT

FOSRC

FHLR 


\section{FHLT}

FWSAT

FGSAT

WOPR

'PROD1'

I

WGPR

'PROD1'

I

WSTPR

'PROD1'

I

WWPR

'PROD1'

/

WEGR

'PROD1'

I

WTEMP

I

WEOR

'PROD1'

I

WEWR

'PROD1'

I

WERW

'PROD1'

I 
WBHP
WSTPR
'PROD1'
$/$
WSTPT
'PROD1'
$/$
WSQU
'PROD1'
/
-- Performance data

PERFORMANCE

-- Run summary file

RUNSUM

SCHEDULE $===========================================$

--RPTSCHED

--PRES TEMP ENERGY SOIL SWAT SGAS /

WELSPECS

PROD1 11511550 OIL/

INJ1 11151550 WATER/

I

COMPDAT

--well - location - open satn trans well kh $\mathrm{S}$ D direct

-- name i j k1 k2 shut tab factor diam

PROD1 15 11110 OPEN $1 * \begin{array}{lllllll} & 0.0 & 0.5833 & 4 *\end{array}$

INJ1 115110 OPEN $1 * \begin{array}{lllllll} & 0.0 & 0.5833 & 4 *\end{array}$

I

WCONINJE 
--Well Type ... Init Rate Res BHP-

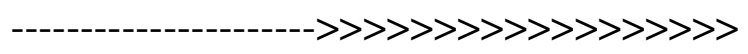

INJ1 WATER OPEN RATE $501 * 1000$ /

I

WINJTEMP

--Well SQ Temp

INJ1 $0.7450 \quad /$

/

-- Production targets

WCONPROD

--Well ... Init Oil Wat Gas Liq Res BHP ... Steam

PROD1 OPEN BHP 3* $701 * 1006^{*}$ /

I

TSCRIT

--initT minT maxT maxInc/Dec targTTE maxTTE TTPT MTPT TSCT MxWT

$2.011^{*} 1^{*} 1^{*} \quad 1^{*} \quad 1 * \quad 1 * 1 * 2.5365$

--maxPT maxSC ATPT SACT maxSA TEMT maxTEM

$1 * \quad 1^{*} \quad 1^{*} 1^{*} \quad 1^{*} \quad 180300 /$

TSTEP

$48 * 50$ /

WCONINJE

--Well Type ... Init Rate Res BHP-

INJ1 WATER OPEN RATE $5001 * 1000 /$

/

WINJTEMP

--Well SQ Temp BHP

INJ1 $1 * 861000$ /

I 


\section{WCONPROD}

--Well ... Init Oil Wat Gas Liq Res BHP ... Steam

PROD1 OPEN BHP 3* 250 1*100 6* /

/

TSTEP

$80 * 50 /$

END 


\section{VITA}

Name:

Education:

Email:

Address:
Akkharachai Limpasurat

B.Eng., Petroleum Engineering

Chulalongkorn University

Faculty of Engineering

Chulalongkorn University

Patumwan, Bangkok, 10330, Thailand

March 2005

M.S., Petroleum Engineering

Texas A\&M University

407 H Richardson Building

College Station, TX 77843-3116, USA

August 2010

Akkharachai.1@pe.tamu.edu

407 H Richardson Building

College Station, TX 77843-3116, USA 